\title{
Prediction of the Impact of Tower Shading on Resource Parameters and Performance by Using LiDAR
}

\author{
Maduako E. Okorie \\ PhD Student, \\ University of KwaZulu-Natal, Durban, South Africa.
}

\author{
Freddie Inambao* \\ University of KwaZulu-Natal, Durban, South Africa. \\ ORCID: 0000-0001-9922-5434 (Freddie Inambao) \\ *Corresponding author.
}

\begin{abstract}
Accurate identification and definition of tower wake boundaries for wind measurement is crucial for site representative wind characterization and economic evaluation. Besides computational and wind tunnel approaches, other methods utilized in field experiments to identify tower waked direction sectors are traditional speed ratio and the coefficient of determination $\left(\mathrm{R}^{2}\right)$ of turbulent kinetic energy (TKE), and turbulence intensity (TI) of collocated sensors. In a situation where collocated sensors are not available, and wind data are collected from two intermediate heights with the same azimuth angle from the north, typical of majority of the National Wind Resources Assessment Project (NWRAP) wind measurement sites, the traditional approaches are limited in their applications. Therefore, in this current study, a new, simpler, and more useful approach to identifying and defining waked boundaries is proposed. In this approach, time series wind shear coefficients (WSCs) are computed, binned in appropriate wind direction bins $\left(\leq 5^{\circ}\right.$ to reduce averaging effect) and drawn as a function of wind direction. At Amperbo, time series WSC computed between the height intervals $8.68 \mathrm{~m}$ to $16.88 \mathrm{~m}, 16.88 \mathrm{~m}$ to $32.68 \mathrm{~m}, 16.88 \mathrm{~m}$ to $64.92 \mathrm{~m}$ and $32.68 \mathrm{~m}$ to 64.92 defined wake boundaries covering an angle of approximately $60^{\circ}$ each, when compared with time series WSC calculated using undisturbed LiDAR data at corresponding height intervals, and this is in agreement with the approximately $60^{\circ}$ span defined by the traditional approach. Similarly, at Schlip, time series WSC computed between $20.63 \mathrm{~m}$ to $49.9 \mathrm{~m}$ defined a wake boundary of approximately $70^{\circ}$ and the result is again supported the traditional speed ratio approach that defined a wake boundary of approximately $70^{\circ}$. Two statistical models (Weibull and Raleigh) could not properly characterize the wake affected zones and the mean value of Weibull $\mathrm{c}$ were found to be in the range of $12 \%$ to $14 \%$ higher than the observed mean speed at both sites. Furthermore, wind power density (WPD) was found to be grossly underpredicted in the wake affected direction sectors. At Amper-bo, the WPD obtained showed a consistent underestimation, $>95 \%$ for the observed and for the models in the severely affected direction sectors. At Schlip, WPD also showed a consistent underprediction of $>73$ $\%$ for the observed and the models in the severely affected direction sectors. When the wake affected direction sectors were removed, the mean speed, mean value Weibull $\mathrm{c}$ and the mean WPD improved. Finally, insight gained from thorough description of the wind rose shows that wake affected sectors
\end{abstract}

are characterized with disproportionally higher percentages of low wind regimes when compared to other sectors and this is contrary to the LiDAR observation in the corresponding sectors.

Keywords: Tower shading, resource parameters, wind shear coefficients, wind power density and Weibull models

\section{INTRODUCTION}

'Tower wake distortion effect' describes the uncertainty introduced to wind data captured using boom mounted anemometers placed on the top or at some intermediate heights of a tower, due to tower induced flow modifications which result in the underprediction of the local wind speeds in the wake and associated speed-ups in the upwind side of the tower. Previous literature [1]-[10] has reported tower induced flow defects in the form of wind speed deficits in the waked regions and speed-ups in the upwind side of the tower. Using computational fluid dynamics (CFD) flow analysis and wind tunnel experiments, literature such as [4] and [11]-[14] have revealed an order of increased turbulence intensity (TI) and impact of freestream turbulence in tower shadings. Some of the studies, however, opined that an increase in upstream turbulence intensity (TI) and freestream turbulence do not significantly affect flow modification within the vicinity of the tower. Studies that have validated in-situ with light detection and ranging (LiDAR) captured data [2], [15] also reported an order of increase in turbulent kinetic energy (TKE) and TI due to tower wake effects.

Besides the obvious speed deficit, speed-ups and increase in TI and TKE reported, there is a need to further characterize the exact impact of tower wake distortion effects on these parameters and other resource parameters of interest against the undisturbed LiDAR observed data. This study, therefore, investigated the impact of tower wake distortion on resource parameters and performance. The tower shadow impact on wind shear trend and coefficients, and other site-specific statistics predicted with probability density functions (Weibull and Rayleigh), were quantified and compared with undisturbed LiDAR data. Besides the common and universally accepted approach of filtering and discarding wind data in the wake affected regions, the current work proposes a new approach to identifying and removing wake affected direction sectors where collocated sensors are not available and wind data are collected from two intermediate heights, with the boom 
orientation on the same azimuth from the north. This approach leverages on the relationship between the observed wind speed and other resource parameters.

The impact of tower wake on the selected parameters were further evaluated and compared to the LiDAR for performance evaluation, with the aim of understanding how the tainted data propagates into the wind power density (WPD). This study contributes to literature and further reveals why stringent/strict best practices and approaches must be adhered to in placing instruments for wind measurement on operational towers of any configuration to minimize or remove entirely the effect of tower shading. Finally, the study will answer the question "what are the performance implications of not removing wake affected direction sectors?".

\section{BACKGROUND}

As part of the National Wind Resource Assessment Project (NWRAP) of Namibia, two study areas where wind data were concurrently being acquired (2014) using anemometers mounted on communication towers and LiDAR are analyzed and reported. The first site $\left(25.354^{\circ} \mathrm{S}, 18.313^{\circ} \mathrm{E}\right)$ is an inland farm settlement called Amper-bo in the Hardap region of southern Namibia. It is $1152 \mathrm{~m}$ above sea level. The terrain is flat, and the orography gentle so can be classified as class A terrain according to Annex $\mathrm{G}$ of [16], [17]. The tower is a 120 $\mathrm{m}$ lattice triangular communication tower belonging to the Mobile Telecommunication Limited (MTC) of Namibia and is heavily instrumented with a huge number of sensors at various heights. The brief construction detail is found in [2], [18]. A ground profiler, QinetiQ Ltd (UK) ZephIR Z300 LiDAR was installed at approximately $5.4 \mathrm{~m}$ from the foot of the tower to enable data comparison and tower shadow identification. It is a homodyne continuous wave $(\mathrm{CW})$ Doppler wind LiDAR system with 10 user programmable heights (besides a pre-fixed height of $38 \mathrm{~m}$ ) up to $200 \mathrm{~m}$, with a minimum measurement height of $10 \mathrm{~m}$ was operational from $16^{\text {th }}$ Jan. 2014 to $30^{\text {th }}$ Sept. 2014. The brief detailed specifications and operation of ZephIR $\mathrm{Z} 300 \mathrm{LiDAR}$ is found in [18]. The second site $\left(24.030^{\circ} \mathrm{S}\right.$, $17.131^{\circ} \mathrm{E}$ ) is located near Schlip, a farm settlement in the Rehoboth rural constituency in the Hardap region of central Namibia. Wind speeds were measured at two intermediate heights $(20.63 \mathrm{~m}$ and $49.90 \mathrm{~m})$ but at the same azimuth from the north (Table IV) on the $80 \mathrm{~m}$ high communication tower. The construction details are the same as the tower at Amper-bo as reported in [2]. The LiDAR was moved from Amper-bo and was operational from $31^{\text {st }}$ Sept. 2014 to $24^{\text {th }}$ Dec. 2014 at Schlip site. The results from the analysis of the two data sets are reported in this work.

\section{METHODS}

To investigate the relationship between wind speed and WSC and to enable its use for identification and definition of tower waked regions, the shear trend and WSC for both sites were carefully studied and reported. To enable performance evaluation of the waked regions, the probability density functions often used (Weibull and Rayleigh models) to describe a site wind statistic were computed in reference to the observed data (in-situ and LiDAR).

\section{A. Wind Shear Trend and Coefficients}

Accurate site wind speed characterization is the basis for wind power project economic projection and overall site suitability. The growing height of modern-day wind turbines makes it impossible for wind data to always be measured at the hub height of interest, necessitating hub height extrapolation based on wind speeds measured at lower reference heights. Literature (such as [19]-[21]) has reported that shear extrapolation introduces non-negligible errors to the predicted wind speed. The accuracy of the predicted hub height speed depends wholly on how the model used can accurately predict the velocity profile at the site. In the context of this study, three methods were adopted for computing WCS to permit hub height extrapolation. They are one-point theoretical log law, two points power law and multi-points fitted power law.

\section{B. The Two-Point Power Law}

The power law is the model commonly used for wind speed extrapolation. With two wind speeds measured at two different heights, the power law exponent is obtained which is subsequently used in conjunction with a power law to extrapolate to the hub height of interest. A commonly used version of the Hellmann's power law (1) is:

$$
v_{2}=v_{1}\left(\frac{h_{2}}{h_{1}}\right)^{\alpha}
$$

Where wind speed $v_{1}$ is known at a reference height $h_{1}$ and required at a desired height $h_{2}$. Solving for $\alpha$ yields (2).

$$
\alpha=\frac{\operatorname{In}\left(v_{2}\right)-\operatorname{In}\left(v_{1}\right)}{\operatorname{In}\left(h_{m}\right)-\operatorname{In}\left(h_{1}\right)}
$$

The exponent $(\alpha)$, is the WSC considered to be site, time, and height interval dependent [19], [22]. Application of (1) and (2) requires confidence in the observed wind speed. A multi-point fitted power law profile can also be fitted to measurements where three or more heights are available in order to obtain the power law exponent that can be used to predict wind speed at the hub height of interest.

\section{One Point Theoreical Log Law}

The log law originates from boundary layer fluid mechanics. A simpler and a more practical model of the one-point theoretical law derived under the neutral stability assumption (i.e. vertical wind flow in the atmosphere without excitation), (3) utilizes only theoretical considerations to extrapolate a single wind speed from a lower reference height to wind speeds at other hub heights of interest.

$$
v_{2}=v_{1} \frac{\operatorname{In}\left(h_{2} / z_{0}\right)}{\operatorname{In}\left(h_{1} / z_{n}\right)}
$$

where wind speed $v_{1}$ is known at a reference height $h_{1}$ and required at a desired height $h_{2}$. The surface roughness is $\left(z_{0}\right)$. The simplified version of (3) limits its application to terrain of flat and homogenous orography in practice. Worthy of note, however, is that the log law becomes mathematically undefined 
at two heights when $\mathrm{v}_{1}$ at $\mathrm{h}_{1}$ is equal to $\mathrm{v}_{2}$ at $\mathrm{h}_{2}$. On the other hand, a decrease in wind speed with height will give a $\mathrm{z}_{0}$ value that is high but unrealistic. Solving (1) and (3), by eliminating $\mathrm{v}_{1}$ and $\mathrm{v}_{2}$, provides a formula for calculating $\mathrm{z}_{0}$ as reported by Gualtieri and Secci [21].

$$
\mathrm{z}_{0}=\exp \left[\frac{\left.\mathrm{h}_{\mathrm{z} \operatorname{In}\left(\mathrm{h}_{1}\right)}-\mathrm{h}_{\mathrm{1In}\left(\mathrm{h}_{\mathrm{g}}\right)}^{\alpha}\right]}{\mathrm{h}_{\mathrm{z}}^{\alpha}-\mathrm{h}_{1}^{\alpha}}\right]
$$

\section{The Multi-Point Fitted Log Law}

This approach requires fitting a logarithmic profile to measurements where three or more heights are available. The fitted profile is used to predict wind speed at the hub height of interest. According to [23], a good test of how well this approach performs is the correlation coefficient. A good practice is that heights with erroneous data must be removed provided three measurement heights are still available.

\section{E. Turbulence Intensity (T1)}

Turbulence intensity is the ratio of the standard deviation $(\sigma)$ over the mean wind speed (u) as shown in (5):

$$
T I=\sigma / u(5)
$$

\section{F. Wind Power Density (WPD)}

Wind power density (WPD) is a vital resource parameter that provides an indication of the wind power potential of a site as it enables the estimation of how much energy per unit of time and swept area of the blades is available if wind conversion technology is deployed. It is directly related to the specific site air density and to the cube of the wind speed, computed, thus:

$$
\mathrm{WPD}=\frac{1}{\mathrm{n}} \sum_{\mathrm{i}=1}^{\mathrm{i}=\mathrm{n}} \frac{1}{2} \rho \mathrm{u}_{\mathrm{i}}^{3}
$$

Where $u_{i}[\mathrm{~m} / \mathrm{s}]$ and nu are the mean wind speed for the data record $i$ and the total number of data records in that time series respectively, $\rho\left[\mathrm{kg} / \mathrm{m}^{3}\right]$ is the air density which is a function of function of ambient temperature $\mathrm{T}\left[{ }^{\circ} \mathrm{C}\right]$ and pressure $(\mathrm{P})$, both parameters are known to vary with height above sea level $\mathrm{Z}$ [24]. For wind potential estimation at a given hub height, the corresponding $\rho$ is evaluated using (8) as reported in [24]:

$$
\rho=\rho_{0} \frac{T_{0}}{T}\left(1-\frac{\Gamma_{0} z}{T_{n}}\right)^{\frac{g}{T R}}
$$

Where $\mathrm{g}+9.81 \mathrm{~m} / \mathrm{s}$ is the gravitational acceleration, $\mathrm{T}$ is the temperature in Kelvin $[\mathrm{K}], \mathrm{R}=287.08 \mathrm{~J} / \mathrm{kgK}$, is the gas constant,

$$
\mathrm{T}_{\mathrm{n}}=288.15 \mathrm{~K}(=273.15+15)
$$

$\mathrm{T}_{\mathrm{n}}=288.15 \mathrm{~K}(=273.15+15)$ is the vertical temperature gradient, $\mathrm{T}_{\mathrm{n}}=288.15 \mathrm{~K}(=273.15+15)$, $\rho_{0}=1.225 \mathrm{~kg} / \mathrm{m}^{3}$. Parameters with subscript 0 are obtained from the standard atmospheric conditions.

\section{G. Weibull distribution of Wind Speed}

In wind data analysis for power potential estimation, it is ideal to have a few parameters that can satisfactorily describe the generally wide range of wind data captured by various wind observation techniques. Time and resources being of the essence in the majority of the wind assessment projects, a set of statistical functions was employed to describe such variations in wind speed. Probability functions, of which the most used are the Weibull and Rayleigh Probability density functions, are the industry wide accepted statistical approaches [24]-[27]. Probability density function and cumulative distribution $\mathrm{F}(\mathrm{v})$ are the two-parameter functions used by the Weibull approach to describe wind speed variation, typical of actual site observed wind data. The $f(v)$ is the frequency of occurrence of wind speed (v) in a frequency distribution. Its expression is given by:

$$
f(v)=\frac{k}{c}\left(\frac{v}{c}\right)^{k-1} \times \exp \left[-\left(\frac{v}{c}\right)^{k}\right]
$$

Where $k$ is the empirical Weibull shape factor which captures the spread of the wind speed, and $c[\mathrm{~m} / \mathrm{s}]$ is the empirical Weibull scale factor which shows how windy a site is. As a continuous distribution $F(v)$ of the wind speed (v) is the integral of the $F(v)$ and it gives the probability that the wind speed is $\leq \mathrm{v}$. It is calculated thus:

$$
\mathrm{F}(\mathrm{v})=1-\exp \left[-\left(\frac{\mathrm{v}}{\mathrm{c}}\right)^{\mathrm{k}}\right]
$$

Several methods have been used to determine the Weibull $c$ and $k$ to enable proper description of the site wind regime [28]. In this study, a graphical approach which leverages on the transformation of the cumulative distribution function into a linear form by taking double logarithm of equation of equation 9 was adopted, and it follows that:

$$
\operatorname{In}\{-\operatorname{In}[1-\mathrm{F}(\mathrm{v})]\}=\mathrm{k} \operatorname{In}(\mathrm{v})-\mathrm{kIn}(\mathrm{c})
$$

The graphical representation of $\operatorname{In}(\mathrm{v})$ and $\operatorname{In}\{-\operatorname{In}[1-\mathrm{F}(\mathrm{v})]\}$ yields a straight line with a slope of $\mathrm{k}$ and intercept with the abscissa of $(-k \operatorname{In}(c))$. The values of $k$ and $c$ are obtained by the slope of the line of best fit to the straight line graph and the intercept with the ordinate respectively.

According to [25], the WPD for Weibull function is calculated thus:

$$
\mathrm{WPD}=\frac{1}{2} \rho c^{3} \Gamma\left[1+\frac{3}{\mathrm{k}}\right]
$$

\section{DATA DESCRIPTION}

At both sites, the wind data concurrently observed in 2014 by the two measurement techniques were analyzed and reported. At Amper-bo the LiDAR observed data was for 8.4 months (16 $6^{\text {th }}$ Jan. 2014 to $30^{\text {th }}$ Sept. 2014) and at Schlip for nearly 3 months ( $31^{\text {st }}$ of Sept. to $24^{\text {th }}$ of Dec. 2014). The operating range and accuracy of the sensors are summarized in Table I. Table II shows the sensor arrangement details at the Amper-bo site. Table III gives a summary of the mean speed captured by the LiDAR from the 10 user programmed heights at a pre-fixed height of $38 \mathrm{~m}$. The wind speed captured by LiDAR at Amper- 
International Journal of Engineering Research and Technology. ISSN 0974-3154, Volume 13, Number 11 (2020), pp. 3125-3144

(C) International Research Publication House. https://dx.doi.org/10.37624/IJERT/13.11.2020.3125-3144

bo is denoted as LiDAR wind speed (LWS) and at Schlip, it is denoted as Schlip LiDAR wind speed (sLWS). The brief operating range and accuracy of the LiDAR is reported in [2].

TABLE I. OPERATING RANGES AND ACCURACIES OF VARIOUS SENSORS USED FOR DATA ACQUISITION

\begin{tabular}{|l|l|l|l|l|}
\hline S. no & Parameter & Sensor type & Operating range & Accuracy \\
\hline 1 & Wind speed & NRG\#40 Maximum anemometer & $1.0-96 \mathrm{~m} / \mathrm{s}$ & $0.1 \mathrm{~m} / \mathrm{s}$ \\
\hline 2 & Wind vane & NRG\#200P Wind direction vane & $0-360^{\circ}$. & $1^{\circ}$ \\
\hline 3 & Temperature & NRG\#110S with solar radiation shield & $-40-52.5^{\circ} \mathrm{C}$ & $\pm 1.78^{\circ} \mathrm{C}$ \\
\hline 4 & $\begin{array}{l}\text { Relative } \\
\text { Humidity }\end{array}$ & RH-5 Relative humidity sensor & $5-95 \%$ & $\pm 5 \% \mathrm{RH}$ \\
\hline 5 & Pressure & NRG\#BP20 Barometric pressure sensor & $15-115 \mathrm{kPa}$ & $\pm 1.5 \mathrm{kPa}$ \\
\hline
\end{tabular}

TABLE II. INSTRUMENTATION DETAILS OF AMPER-BO EXPERIMENT IN 2014

\begin{tabular}{|l|l|l|l|l|}
\hline & \multicolumn{2}{|l|}{ August 2012 Arrangement } & \multicolumn{2}{l|}{ March 27, 2014 Arrangement } \\
\hline Sensors & Heights $(\boldsymbol{m})$ & Angle $(\boldsymbol{\phi})$ degree & Height $(\boldsymbol{m})$ & Angle $(\boldsymbol{\phi})$ degree \\
\hline WS1 & 3.88 & 159 & - & - \\
\hline WS2 & 4.88 & 159 & - & - \\
\hline WS3 & 8.68 & 159 & 8.68 & 159 \\
\hline WS4 & 16.88 & 159 & 16.88 & 159 \\
\hline WS4B & - & - & 16.88 & 278 \\
\hline WS5 & 32.68 & 160 & 32.68 & 160 \\
\hline WS6 & 64.92 & 160 & 64.92 & 160 \\
\hline WS6B & - & - & 64.92 & 278 \\
\hline WS7 & 120.38 & 159 & 120.38 & 159 \\
\hline WD1 & 4.88 & 38 & 4.88 & 38 \\
\hline WD2 & 16.88 & 38 & 16.88 & 38 \\
\hline WD3 & 64.92 & 38 & 64.92 & 38 \\
\hline WD4 & 120.38 & 279 & 120.38 & 279 \\
\hline
\end{tabular}

TABLE III. MEAN SPEED CAPTURED BY THE LIDAR AT AMPER-BO IN 2014

\begin{tabular}{|l|l|l|l|l|l|l|l|l|l|l|l|}
\hline $\begin{array}{l}\text { Height } \\
(\mathbf{m} / \mathbf{s})\end{array}$ & 10 & 17 & 33 & 38 & 49 & 65 & 75 & 90 & 12 & 150 & 200 \\
\hline Sensor & LWS1 & LWS2 & LWS3 & LWS4 & LWS5 & LWS6 & LWS7 & LWS8 & LWS9 & LWS10 & LWS11 \\
\hline $\begin{array}{l}\text { Mean } \\
\text { speed } \\
(\mathbf{m} / \mathbf{s})\end{array}$ & 3.73 & 4.26 & 5.21 & 5.46 & 5.81 & 6.25 & 6.46 & 6.73 & 7.09 & 7.33 & 7.54 \\
\hline
\end{tabular}

At Schlip, wind speeds were measured at two intermediate heights and Table IV is a summary of the sensor instrumentation detail and mean speed using the communication tower. Table $\mathrm{V}$ summarizes the mean speed captured by the LiDAR from the 8 user programmed heights and a pre-fixed height of $38 \mathrm{~m}$. Wind speed increases with heights as expected (Table III, Table IV and Table V). 
International Journal of Engineering Research and Technology. ISSN 0974-3154, Volume 13, Number 11 (2020), pp. $3125-3144$

(C) International Research Publication House. https://dx.doi.org/10.37624/IJERT/13.11.2020.3125-3144

TABLE IV. INSTRUMENTATION DETAILS AT SCHLIP IN 2014

\begin{tabular}{|l|l|l|l|}
\hline Sensors & Heights $(\mathbf{m})$ & Angle $(\boldsymbol{\phi})$ degree & Mean speed $(\mathbf{m} / \mathbf{s})$ \\
\hline WS8 & 20.63 & 161 & 4.66 \\
\hline WS9 & 49.90 & 163 & 5.31 \\
\hline WD5 & 49.90 & 283 & - \\
\hline
\end{tabular}

TABLE V. MEAN SPEED CAPTURED BY THE LIDAR AT SCHLIP IN 2014

\begin{tabular}{|l|l|l|l|l|l|l|l|l|}
\hline Height $(\mathbf{m} / \mathbf{s})$ & 10 & 20 & 38 & 52 & 80 & 100 & 120 & 150 \\
\hline Sensor & sLWS1 & sLWS2 & sLWS3 & sLWS4 & sLWS5 & sLWS6 & sLWS7 & sLWS8 \\
\hline Mean speed $(\mathbf{m} / \mathbf{s})$ & 3.73 & 4.26 & 5.21 & 5.46 & 5.81 & 6.25 & 6.46 & 6.73 \\
\hline
\end{tabular}

\section{DATA RECOVERY RATE}

Data recovery rate expresses the percentage of the valid data points to the possible data points. The recovery rate of the insitu measurement at Amper-bo and Schlip evaluated for this study was $100 \%$. At Amper-bo, the LiDAR recorded a consistent data recovery rate at all heights $>95 \%$, except the two topmost heights $(150 \mathrm{~m}$ and $200 \mathrm{~m})$ where the data availabilities were $94.86 \%$ and $81.47 \%$ respectively (Fig. 1a).

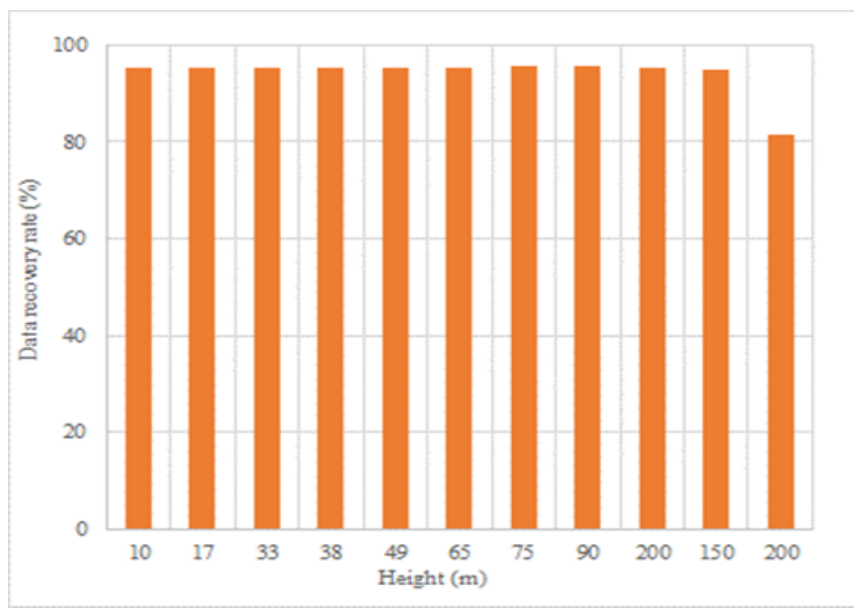

Fig. 1a LiDAR data recovery rate at Amper-bo.

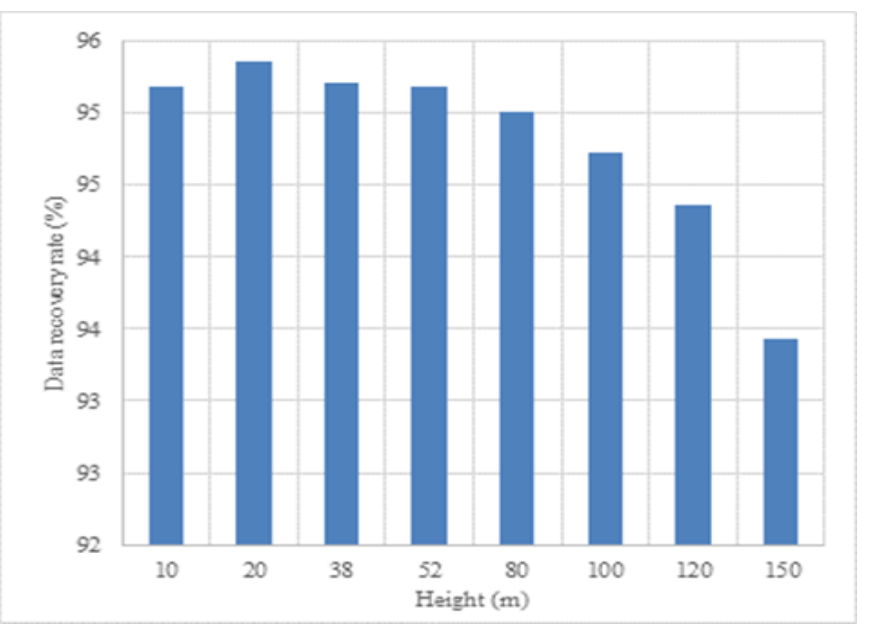

Similar data availability patterns were recorded when the ground profiler was installed at Schlip with recovery rates at all heights $>95 \%$, except the three topmost heights $(100 \mathrm{~m}, 120$ $\mathrm{m}$ and $200 \mathrm{~m}$ ) where the recovery rates were $94.86 \%$ and $81.47 \%$ respectively (Fig. $1 \mathrm{~b}$ ). This trend may be attributed to weak backscatter signal which is difficult for the LiDAR to detect due to large beam waist radius and measurement probe depth at such heights [29]. Data losses within the first four months of the campaign at Amper-bo was mainly due to power failure.

\section{WIND ROSE AND SITE CHARACTERISTICS}

Fig. 2 shows the wind rose diagrams from the Amper-bo and Schlip experiments. The terrains of both sites are relatively flat, therefore the influence of the orography is not detected; hence the similarity in distribution of winds captured by the two observation techniques. At Amper-bo, the wind pattern of WS6 and WS4 captured by the in-situ method are the same (Fig. 2a and Fig. 2b). Similar behavior is evident with LWS6 and LWS2 captured by LiDAR (Fig. 2c and Fig. 2d). At $64.92 \mathrm{~m}$ (WS6), the predominant range of mean speed was $5 \mathrm{~m} / \mathrm{s}$ to 10 $\mathrm{m} / \mathrm{s}(52.27 \%)$, followed by $0 \mathrm{~m} / \mathrm{s}$ to $5 \mathrm{~m} / \mathrm{s}(40.1 \%)$ and $10 \mathrm{~m} / \mathrm{s}$ to $15 \mathrm{~m} / \mathrm{s}(7.48 \%$ ) (Fig. $2 \mathrm{a})$, whereas at $16.88 \mathrm{~m}$ (WS4) the dominant range was $0 \mathrm{~m} / \mathrm{s}$ to $4 \mathrm{~m} / \mathrm{s}(51.28 \%)$, followed by 4 $\mathrm{m} / \mathrm{s}$ to $8 \mathrm{~m} / \mathrm{s}(45.03 \%)$ and $8 \mathrm{~m} / \mathrm{s}$ to $12 \mathrm{~m} / \mathrm{s}$ (3.54\%) (Fig. 2b). Again, at $64.92 \mathrm{~m}$ (Fig. 2a), a most frequent SE-SSE is recorded $(8.41 \%)$, while NNW-N $(8.34 \%)$ and SW-WSW $(8.06 \%)$ are the second and third predominant directions respectively.

Also, at $16.88 \mathrm{~m}$ (Fig. 2b), a prevalent SE-SSE occurs $(8.55$ $\%)$, while NNW-N $(7.88 \%)$ and SSE-S $(7.76 \%)$ are the secondary predominant directions. The strongest wind from WS6 $(64.92 \mathrm{~m})$ and WS4 $(16.88 \mathrm{~m})$ are from the SE-SSE direction sectors. At Amper-bo, for the LiDAR observation, at $65 \mathrm{~m}$ (LWS6), the predominate range of mean speed was $5 \mathrm{~m} / \mathrm{s}$ to $10 \mathrm{~m} / \mathrm{s}(52.33 \%)$, followed by $0 \mathrm{~m} / \mathrm{s}$ to $5 \mathrm{~m} / \mathrm{s}(36 \%)$ and 10 $\mathrm{m} / \mathrm{s}$ to $15 \mathrm{~m} / \mathrm{s}(9.56 \%$ ) (Fig. $2 \mathrm{c}$ ), whereas at $17 \mathrm{~m}$ (LWS2) the dominant range was $4 \mathrm{~m} / \mathrm{s}$ to $8 \mathrm{~m} / \mathrm{s}(51.05 \%)$, followed by 0 $\mathrm{m} / \mathrm{s}$ to $4 \mathrm{~m} / \mathrm{s}(45.6 \%)$ and $8 \mathrm{~m} / \mathrm{s}$ to $12 \mathrm{~m} / \mathrm{s}(3.24 \%)($ Fig. $2 \mathrm{~d})$.

Fig. 1b. LiDAR data recovery rate at Schlip. 


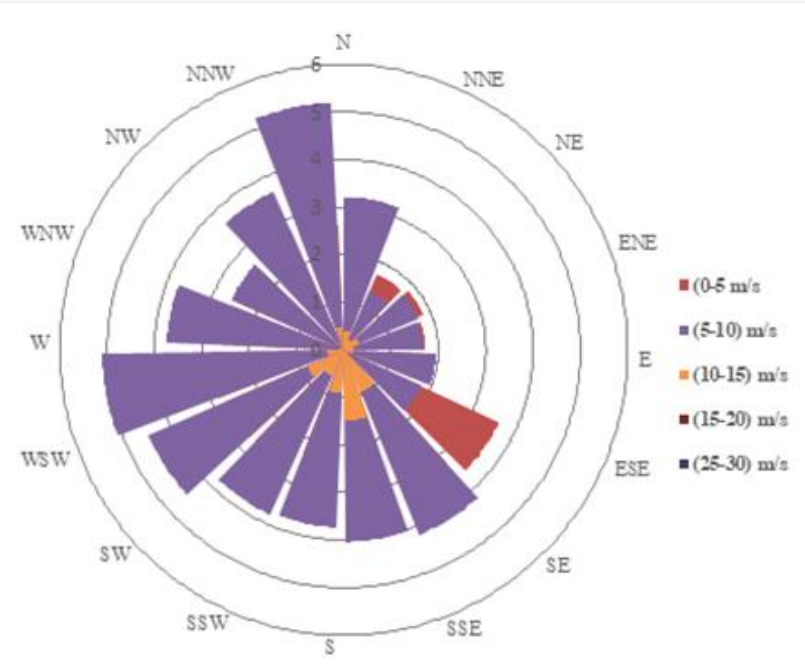

Fig. 2a. Wind rose of WS4 (16.88 m) measured at Amber-bo.

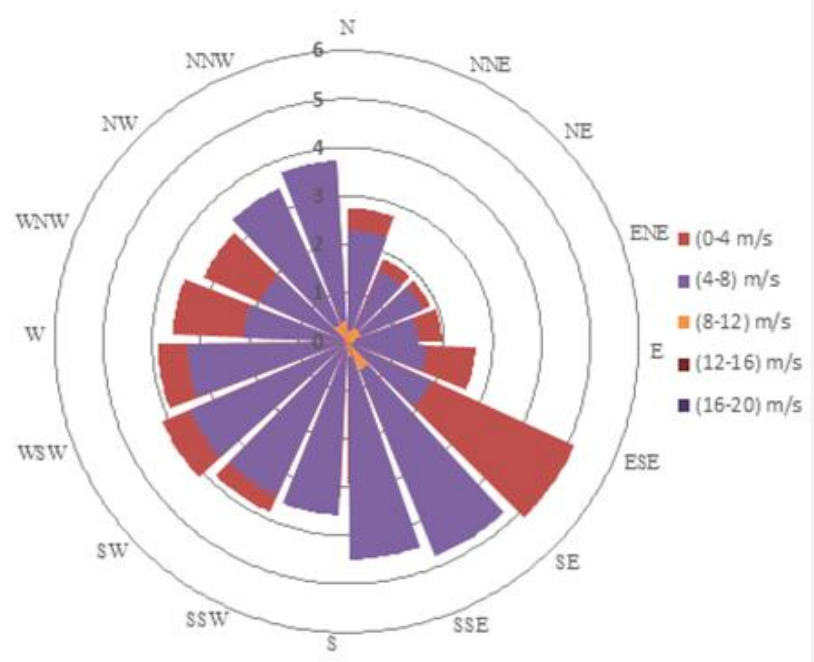

Fig. 2b. Wind rose of WS6 (64.92 m) measured at Amber-bo.

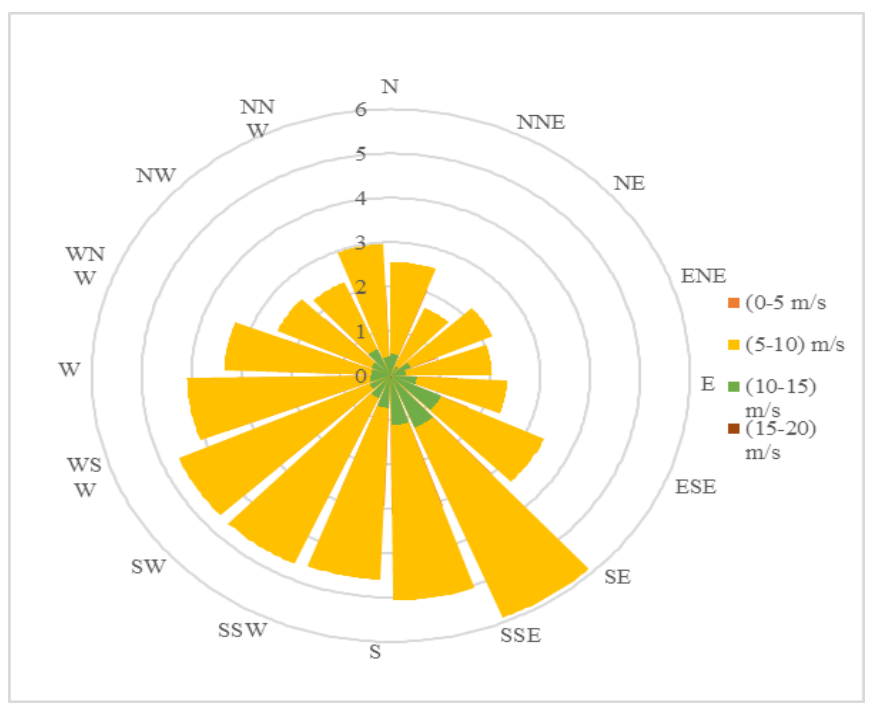

Fig. 2c. Wind rose of LWS6 (65 m) measured at Amper-bo.

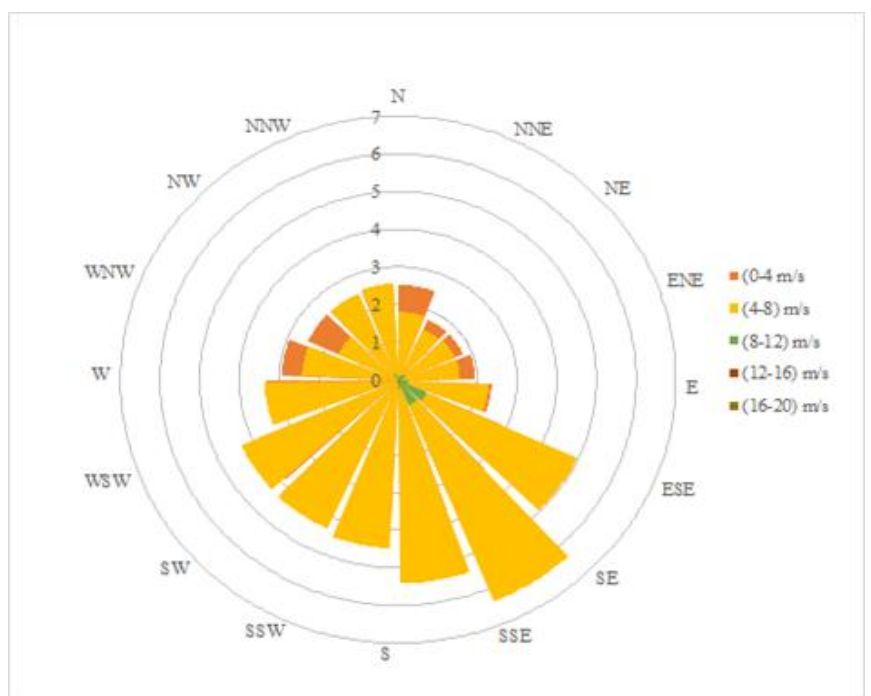

Fig. 2d. Wind rose of LWS2 (17 m) measured at Amper-bo.

Again, at $65 \mathrm{~m}$ (Fig. 2c), a most frequent SE-SSE is recorded (10.12 \%), while SSE-S (9.36 \%) and SW-WSW (9.09\%) are the second and third predominant directions respectively. Also, at $17 \mathrm{~m}$ (Fig. 2d), a prevalent SE-SSE occurs (10.38\%), while SSE-S $(9.31 \%)$ and SSW-SW $(8.61 \%)$ are the secondary predominant directions. The strongest wind from $65 \mathrm{~m}$ (LWS4) and $17 \mathrm{~m}$ (LWS2) are also from SE-SSE direction sectors. However, in the direction sector where tower shadow influence is most severe (ESE-SE), the percentage of wind speed between $0 \mathrm{~m} / \mathrm{s}$ and $4 \mathrm{~m} / \mathrm{s}$ is disproportionally high $(65.38 \%)$ for WS6 and $(71.99 \%)$ for WS4 compared to other wind regimes in the other direction sectors, which is contrary to the undisturbed LiDAR observation within ESE-SE.

At the Schlip experiment, similar evaluations were performed based on WS9 $(49.9 \mathrm{~m})$ and sLWS4 $(65 \mathrm{~m})$ and the results were as follows: the pattern of distribution of winds for the two acquisition systems were the same.

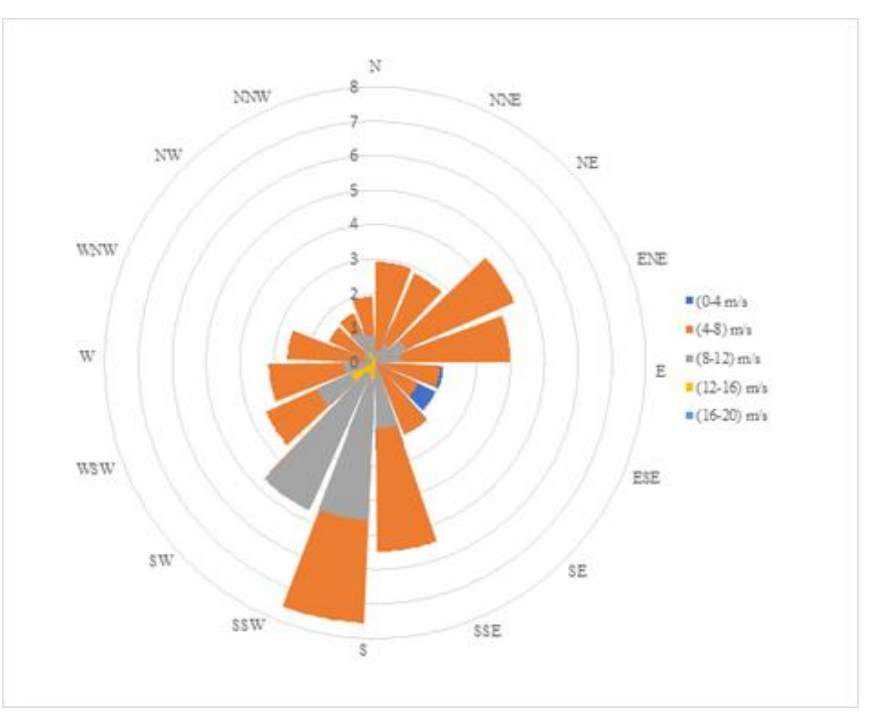

Fig. 2e. Wind rose of sLWS4 (52 m) measured at Schlip. 


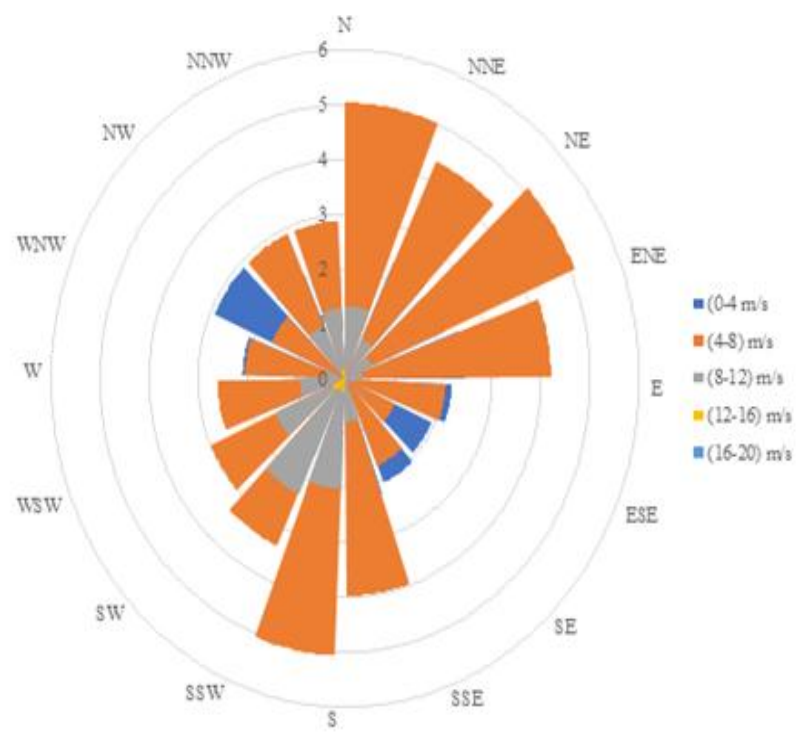

Fig. 2f. Wind rose WS9 (49.9 m) measured at Schlip.

At $49.9 \mathrm{~m}$ (WS9), the range of mean speed that occur most is 4 $\mathrm{m} / \mathrm{s}$ to $8 \mathrm{~m} / \mathrm{s}(51.07 \%)$, followed by $0 \mathrm{~m} / \mathrm{s}$ to $4 \mathrm{~m} / \mathrm{s}(33.68 \%)$ and $8 \mathrm{~m} / \mathrm{s}$ to $12 \mathrm{~m} / \mathrm{s}(13.82 \%$ ) (Fig. 2f), while, at $52 \mathrm{~m}$ (sLWS4) the dominant range is $4 \mathrm{~m} / \mathrm{s}$ to $8 \mathrm{~m} / \mathrm{s}(51.61 \%)$, followed by $0 \mathrm{~m} / \mathrm{s}$ to $4 \mathrm{~m} / \mathrm{s}(26.04 \%)$ and $8 \mathrm{~m} / \mathrm{s}$ to $12 \mathrm{~m} / \mathrm{s}$ (19.56\%) (Fig. 2e). At 49.9 m (Fig. 2f), the most frequent SSSW was recorded $(9.49 \%)$, while N-NNE $(8.84 \%)$ and NEENE $(7.88 \%)$ were the second and third predominant directions respectively. Also, at $51 \mathrm{~m}$ (Fig. 2e), a prevalent S-SSW occurs (14.78\%), while SSW-SW (10.98\%) and SSE-S (10.06\%) are the secondary predominant directions. The strongest wind from $49.9 \mathrm{~m}$ (WS9) and $52 \mathrm{~m}$ (sLWS4) were from the S-SSW direction sector. The direction sector (S-SSW) was severely affected by the tower shading, recording disproportionately high $(65.15 \%)$ wind speed between $0 \mathrm{~m} / \mathrm{s}$ and $4 \mathrm{~m} / \mathrm{s}$ for WS9 when compared to other wind regimes in the other direction sectors which was contrary to the undisturbed Lidar observation withing ESE-SE.

\section{WIND SHEAR TRENDS AND COEFFICIENTS}

At Amper-bo the multi-point fitted power and log law profiles for the 11 different hub heights where LiDAR captured data yields WSCs (power law exponent) and surface roughness of $0.243 \mathrm{~m}$ and $0.626 \mathrm{~m}$ respectively. Using the in-situ data for the following heights $8.68 \mathrm{~m}, 16.88 \mathrm{~m}, 32.68 \mathrm{~m}$ and $64.92 \mathrm{~m}$, multi-point fitted power and log law profiles give WSCs (power law exponent) and surface roughness of $0.259 \mathrm{~m}$ and $0.494 \mathrm{~m}$ respectively. WSC calculated using average wind speeds observed at $16.88 \mathrm{~m}$ and $64.92 \mathrm{~m}$ (Table II) is 0.279 (2). Again, the time series WSC between $16.88 \mathrm{~m}$ and $64.92 \mathrm{~m}$ was calculated and averaged, yielding a WSC value of $0.275 \mathrm{~m} \mathrm{(2)}$. At Amper-bo, based on the in-situ observation, the WSC was calculated using average wind speed at two reference heights
( $16.88 \mathrm{~m}$ and $64.92 \mathrm{~m}$ ) is $7.17 \%$ and $1.43 \%$ higher than values obtained from the multi-point and time series approach respectively. This implies that the magnitude of the WSC obtained was dependent on the computation model applied. The computed roughness lengths appeared higher than normal when compared to values reported for terrains of such orography [19]-[21]. At Schlip a similar approach (multi-point fitted power and log laws) yielded a WSC of 0.135 and $\mathrm{z} 0$ of $0.0225 \mathrm{~m}$ using the three months LIDAR data captured there. For the same data set, using two-point power law, the WSC computed using average wind speeds at $20 \mathrm{~m}$ and $52 \mathrm{~m}$ (Table $\mathrm{V})$ was 0.181 . The time series WSC between $20 \mathrm{~m}$ and $52 \mathrm{~m}$ was further computed and averaged, resulting in a WSC value of 0.143 . Again, using the in-situ measurements performed at two heights (Table IV), in 2014, the multipoint fitted approach gave a WSC of 0.150 and $\mathrm{z} 0$ of $0.0397 \mathrm{~m}$. For the same data set, using the two-point power law, the WSC computed based on the average wind speeds at $20.63 \mathrm{~m}$ and $49.9 \mathrm{~m}$ (Table IV) was 0.148 (2). The time series WSC between $20.63 \mathrm{~m}$ and $49.9 \mathrm{~m}$ was further computed and averaged, resulting in a WSC value of 0.170 (2). At Schlip, based on the in-situ observation, the WSC computed from the time series approach from two reference heights $(20.63 \mathrm{~m}$ and $49.9 \mathrm{~m})$ was $11.76 \%$ and $12.94 \%$ higher than the values obtained from the multi-point and hub heights average wind speed approach, respectively.

In terms of the monthly variation of WSC for both measurements techniques at the two sites, the winter months (May, June and July) accounted for the highest values whereas the summer months (January and December) recorded the lowest values (Fig. 3a and Fig. 3b). This agrees with the findings in the literature review (such as [19]-[21]). This trend is due to thermal stratification of the atmospheric body at both sites [22], [30]. At Amper-bo, both observation techniques recorded a WSC value of 0.37 in June. In January, $\alpha 1$ was 0.18 and $\alpha 2$ was 0.17 . At Schlip, in June and January, $\alpha 3$ and $\alpha 4$ were 0.184 and 0.113 respectively.

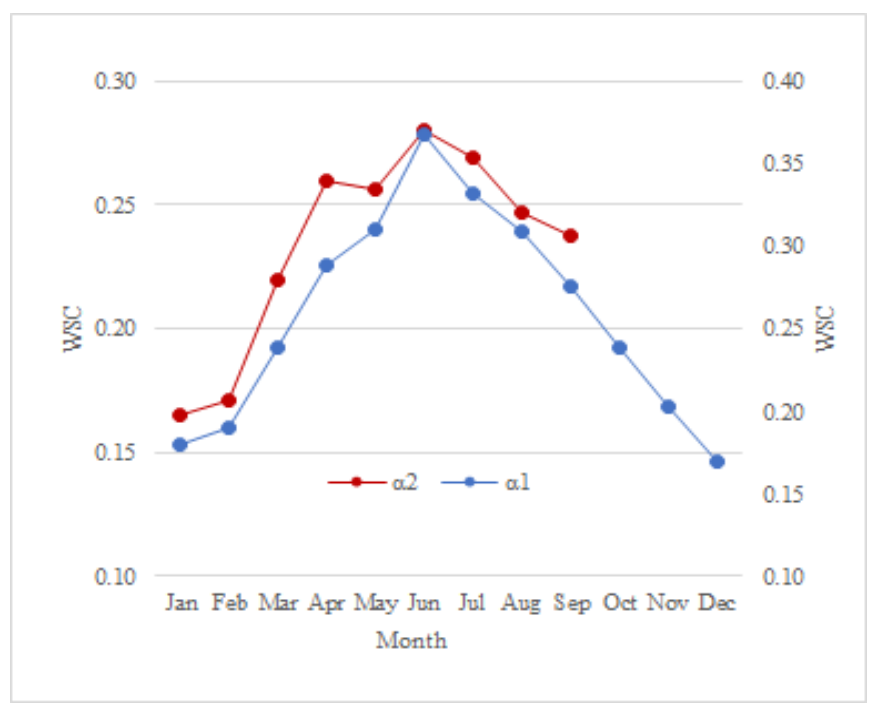

Fig. 3a. Monthly variation of WSC recorded by in-situ $(\alpha 1)$ and LiDAR ( $\alpha 2)$ at Amper-bo in 2014. 


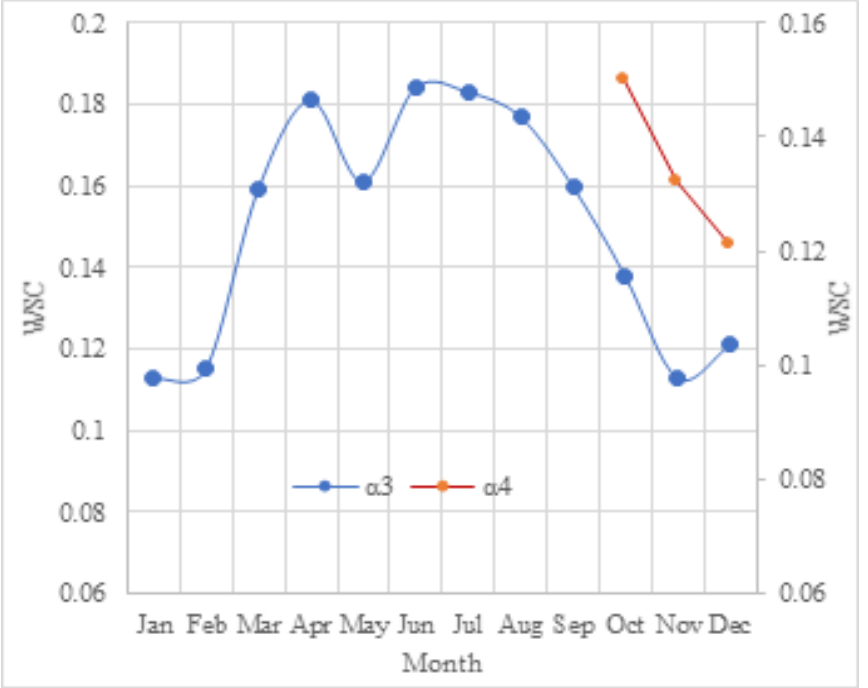

Fig 3b. Monthly variation of WSC recorded by in-situ $(\alpha 3)$ and LiDAR ( $\alpha 4)$ at Schlip in 2014.

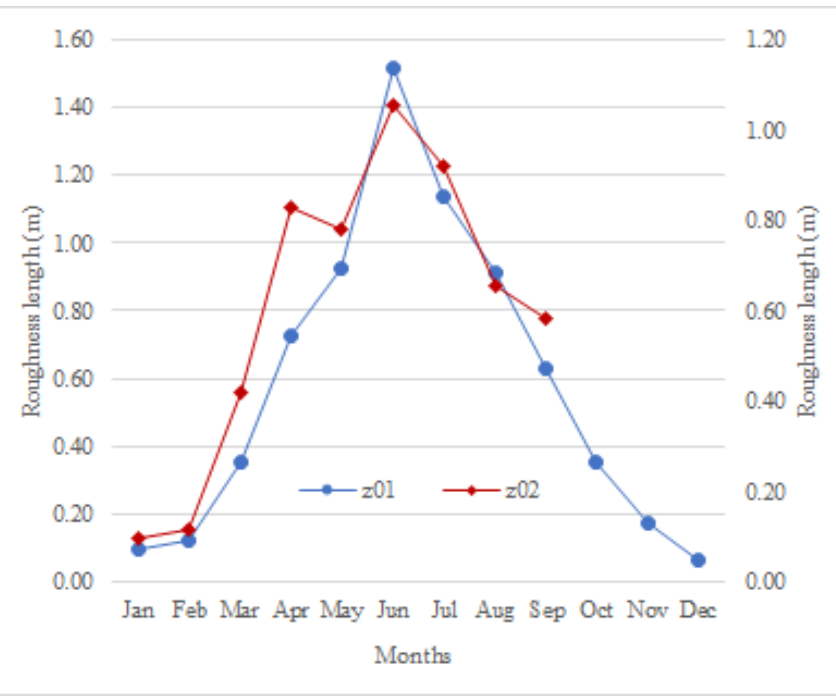

Fig. 3c. Monthly variation of $\mathrm{z} 0$ recorded in-situ (z01) and LiDAR (z02) at Amper-bo in 2014.

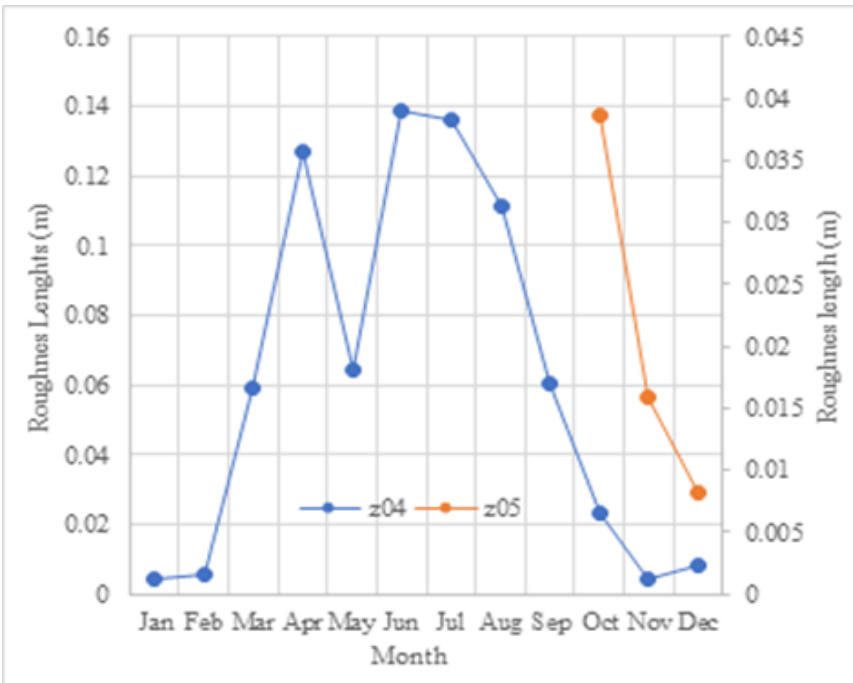

Fig. 3d. Monthly variation of z0 recorded in-situ (z03) and LiDAR (z024) at Schlip in 2014.

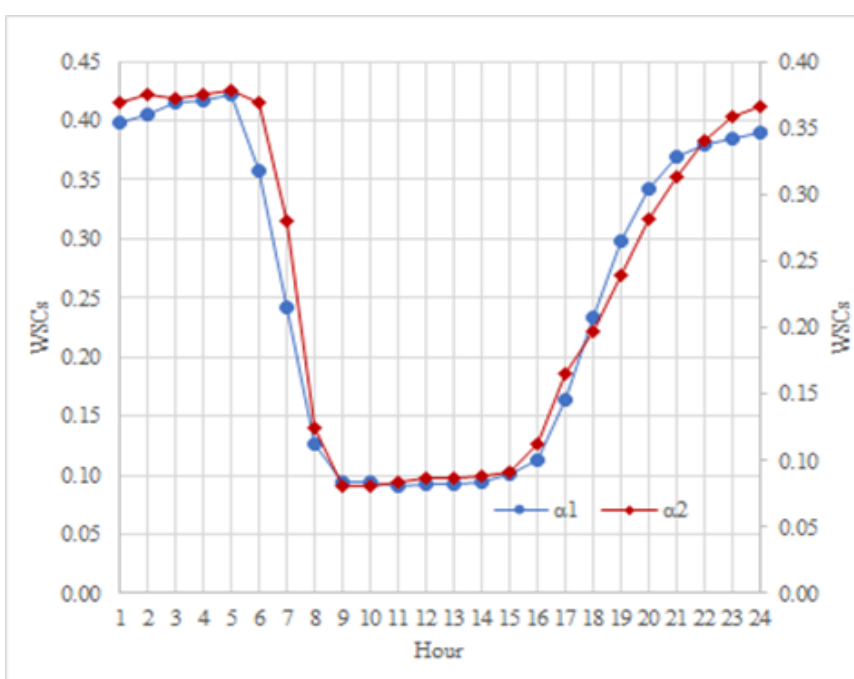

Fig. 3e. Diurnal variation of WSC recorded by in-situ $(\alpha 1)$ and LiDAR ( $\alpha 2)$ at Amper-bo in 2014.

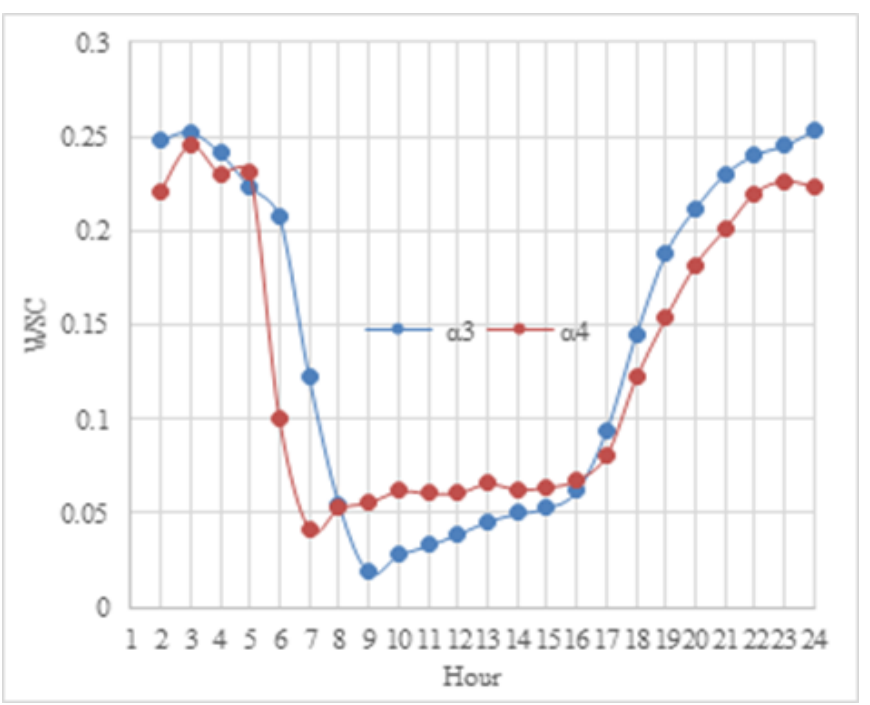

Fig. 3f. Diurnal variation of WSC recorded by in-situ $(\alpha 3)$ and LiDAR $(\alpha 4)$ at Schlip in 2014.

The month of May 2014 is the least windy and that explains the pattern observed in the monthly variations of the $\alpha 3$ and z03 (Fig. 3b and Fig. 3d). The monthly variation of the roughness length has the same patterns as those of WSC, and it is also attributed to the thermal stratification of the atmospheric body at both Amper-bo and Schlip (Fig. 3c and Fig. 3d). Diurnally, the computed WSC at both Amber-bo and Schlip show evidence of direct correlation to the diurnal heating/cooling cycle of air above the ground, and thus of atmospheric stability. Higher values are recorded in the stable night hours whereas the unstable daylight hours account for the lowest values (Fig. $3 \mathrm{~d}$ and Fig. 3e). This pattern is in agreement with several authors (e.g. [20], [31]-[33]. A similar explanation also holds for the pattern of hourly variation of the roughness length at Amper-bo and Schlip as captured by the instruments. 


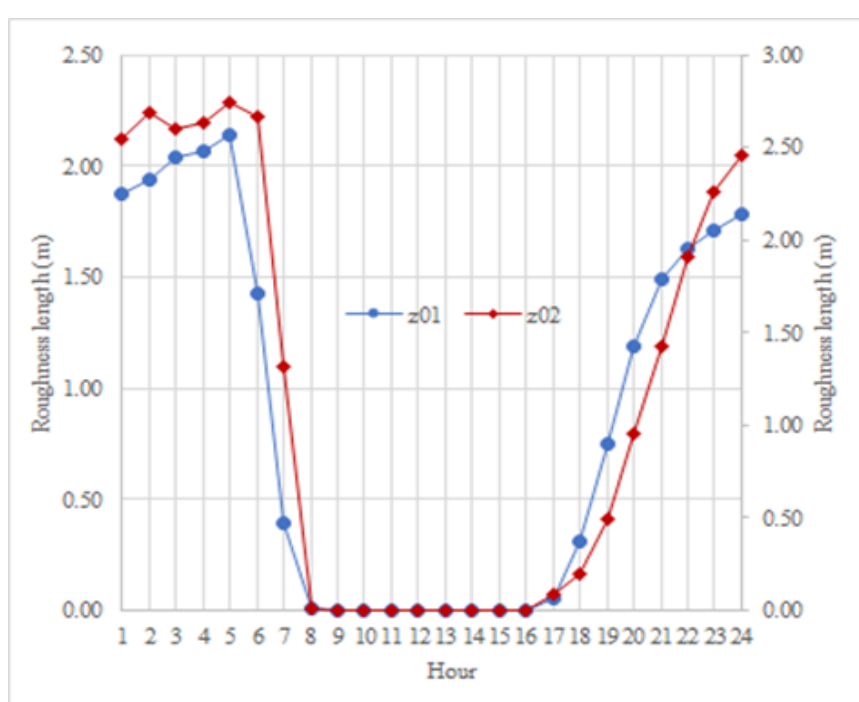

Fig. 3g. Diurnal variation of $\mathrm{z} 0$ recorded in-situ (z01) and LiDAR (z02) at Ampber-bo in 2014.

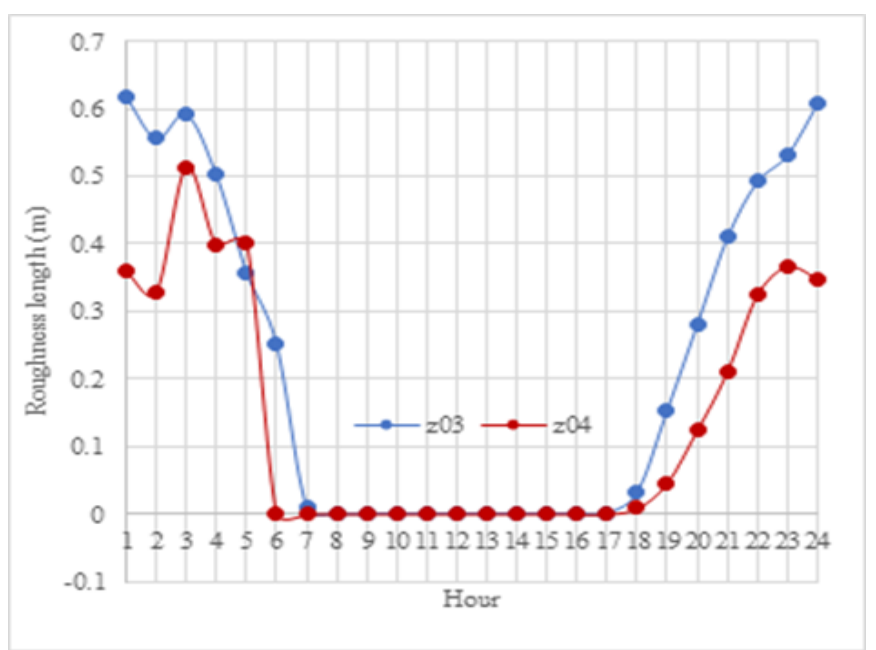

Fig. 3h. Diurnal variation of $\mathrm{z} 0$ recorded in-situ (z03) and LiDAR (z04) at Schlip in 2014.

\section{USING WSC TO DETECT SECTORS AFFECTED BY TOWER WAKES}

A universally accepted norm espoused by many authors in the literature review (such as [2], [16], [17], [34], [35]) for tower wake evaluation and accurate definition of the wake boundaries is the computation of the speed ratios of collocated sensors at the same height of the tower. Other parameters such TEK and TI were used by [2] and [15] for tower wake evaluation. Collocated sensors are commonly placed opposite each other (i.e., at $180^{\circ}$ ) or at $120^{\circ}$ and $60^{\circ}$ apart on triangular lattice masts. For a square lattice tower, collocated speed sensors are aften placed $180^{\circ}$ and $90^{\circ}$ apart because the booms are placed parallel to the face of the tower, and similarly for the lattice triangular tower arrangement. At the Amper-bo experiment, speed sensors were collocated at $16.88 \mathrm{~m}$ and placed $120^{\circ}$ apart. Different approaches were used to precisely define the wake boundaries [2]. Fig. 4 is the speed ratio of the collocated anemometers (WS4 and WS4B) drawn as a function of the wind direction. The wake affected direction sector of WS4 and WS4B are shown.

Where there are no collocated speed sensors (anemometers), but two or three speed sensors (anemometers) are placed at different heights above ground level (AGL) but located on the same azimuth from the north, no literature has addressed a method to detect the error readings of the anemometers as result of tower induced flow perturbations. In this study, WSC $(\alpha)$ was computed from time series data using (2) and drawn as a function of the wind direction at the higher height (h2). The graphs, Fig. 5a, Fig. 5b, Fig. 5c and Fig. 5d clearly show that the WSC variation with direction provided enough information to identify the wake affected sectors. The graphs (Fig. 5a, Fig. 5b, Fig. 5c, and Fig. 5d) are the WSCs binned in $5^{\circ}$ wind direction intervals and plotted as a function of the wind direction. The speed sensors designated WS3, WS4, WS5 and WS6 were placed on the same tower face (Table II), and each sensor's boom azimuth was approximately $160^{\circ}$ from the north. The blue $(\alpha 1)$ and dark red $(\alpha 2)$ lines are WSC variations with directions for in-situ measurements and the ground profiler (LiDAR) respectively at approximately the same height. It has been reported that factors such as site orography/terrain type, heterogeneity of vegetations, possible presence of obstacles and sea/land breezes may be responsible for WSC variation with direction [19], [20]. However, none of these studies considered the impact of tower shading on WSC. As a result, tower shading impact on the directional variation of WSC has not been properly described, with such influence being rather attributed to the orography of those sites investigated.

At Amper-bo, the terrain is flat, the vegetation is almost homogenous at all seasons and there are no near-by obstacles that could significantly influence or modify local flow within the vicinity of the tower except the physical structure of the tower. This explains why the WSC variations (Fig. 5a, Fig. 5b, Fig. 5c and Fig. 5d) for the in-situ and LiDAR observations maintained similar patterns in all direction sectors except the sectors that were exposed to tower induced flow perturbations. The wake affected direction sectors identified by this approach agree with the direction sectors defined by the traditional speed ratio and the coefficient of determination $\left(\mathrm{R}^{2}\right)$ of TI approaches proposed in [2]. Precise definition of wake boundaries and subsequent elimination of the inverse effect of the speed ratio have necessitated the adoption of the $\mathrm{R}^{2}$ approach as shown in Fig. 4. This is the $\mathrm{R}^{2}$ of WS4 and WS4B binned in $1^{\circ}$ wind direction intervals and smoothed with a running average of $2^{\circ}$ and drawn as a function of the wind direction.

The $\mathrm{R}^{2}$ values close 1 indicates a strong positive relation between WS4 and WS4B when neither speed sensors are in the wake. The areas between the vertical dashed lines (Fig. 4) with decreased correction are the areas under the influence of the tower wake. The tower wake boundaries (Fig. 4) were identified to be the direction sectors with $\mathrm{R}^{2}$ values that are less than 2 standard deviations of the mean values of the three nonwaked regions. The wake boundaries cover an angle of approximately $60^{\circ}$. Strictest measure would be to declare every direction sector that falls within 1 standard deviation of the mean values of the three non-waked regions invalid but doing 
so will increase the wake boundaries and reduce the amount of captured data for analysis.

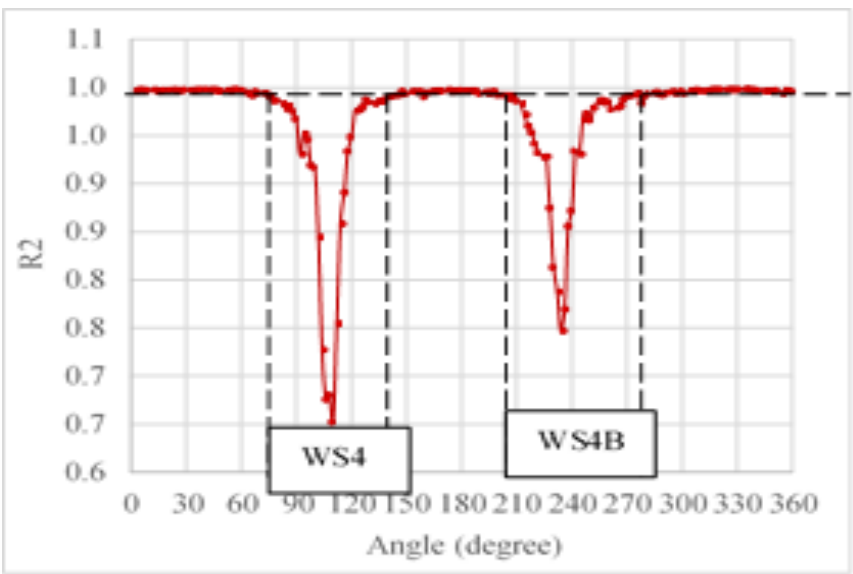

Fig. 4.Coefficient of determination $\left(\mathrm{R}^{2}\right)$ of WS4 and WS4B binned in $1^{\circ}$ wind direction intervals and smoothed with a running average of $2^{\circ}$.

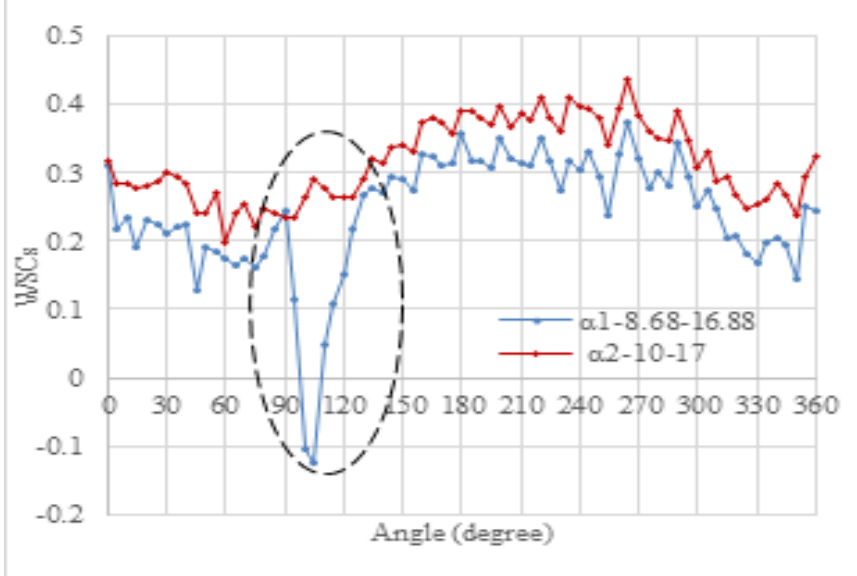

Fig. 5a. Time series WSC calculated for the in-situ $(8.88 \mathrm{~m}$ to $16.88 \mathrm{~m})$ and for the LiDAR $(10 \mathrm{~m}$ to $17 \mathrm{~m})$, binned in $5^{\circ}$ wind direction intervals and drawn as a function of the wind direction.

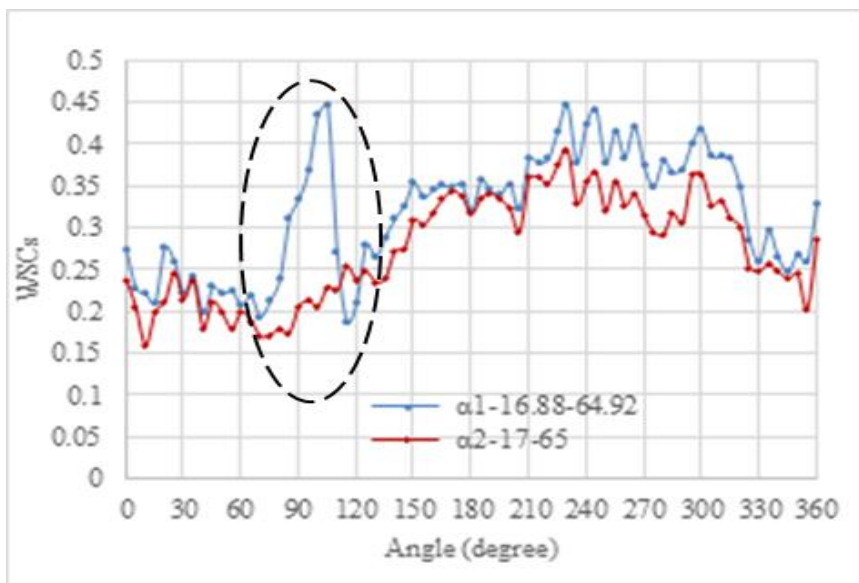

Fig. 5b. Time series WSC calculated for the in-situ $(16.88 \mathrm{~m}$ to $64.92 \mathrm{~m}$ ) and for the LiDAR $(17 \mathrm{~m}$ to $65 \mathrm{~m})$, binned in $5^{\circ}$ wind direction intervals and drawn as a function of the wind direction.

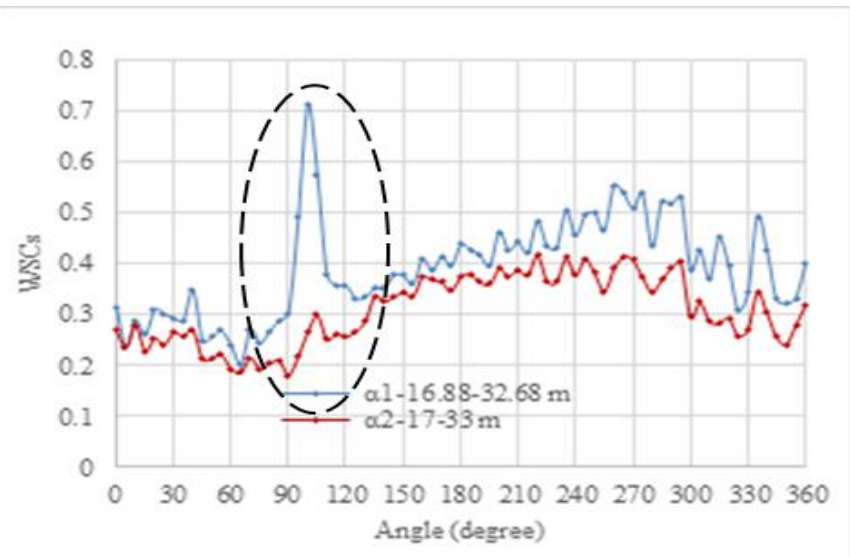

Fig. 5c. Time series WSC calculated for the in-situ $(16.88 \mathrm{~m}$ to $32.68 \mathrm{~m})$ and for the $\operatorname{LiDAR}(17 \mathrm{~m}$ to $33 \mathrm{~m})$, binned in $5^{\circ}$ wind direction intervals and drawn as a function of the wind direction.

The computed WSCs for the in-situ measurement deviate greatly from the LiDAR observations due to tower wakes at all the height intervals considered. The upward and downward displacements noticed (Fig. 5) are directly related to wind speed differences measured by the higher height (hh) and lower height (lh) anemometers. When the higher height anemometer measures wind speeds that are consistently higher than the lower height anemometer, even in the tower waked regions, the deviation is positive from the LiDAR WSC. When speed sensor at $\mathrm{lh}$ measures higher speed than the hh speed sensor, which may occur due to severe speed deficit in the hh sensor, the computed WSCs exhibit lower deviation from the LiDAR values at such an angle. The peak speed deficit occurred between $105^{\circ}$ and $110^{\circ}$, agreeing with the $\mathrm{R}^{2}$ of collocated wind speeds (Fig. 4) and $\mathrm{R}^{2}$ of TI analysis of collocated speed sensors reported in [2]. Time series $\alpha 1$ computed between 8.68 $\mathrm{m}$ and $16.88 \mathrm{~m}$ (in-situ) was compared with $\alpha 2$ computed between $10 \mathrm{~m}$ and $17 \mathrm{~m}$ (LiDAR) and a $57.04 \%$ difference existed at the most severely affected direction sectors (Fig. 5a).

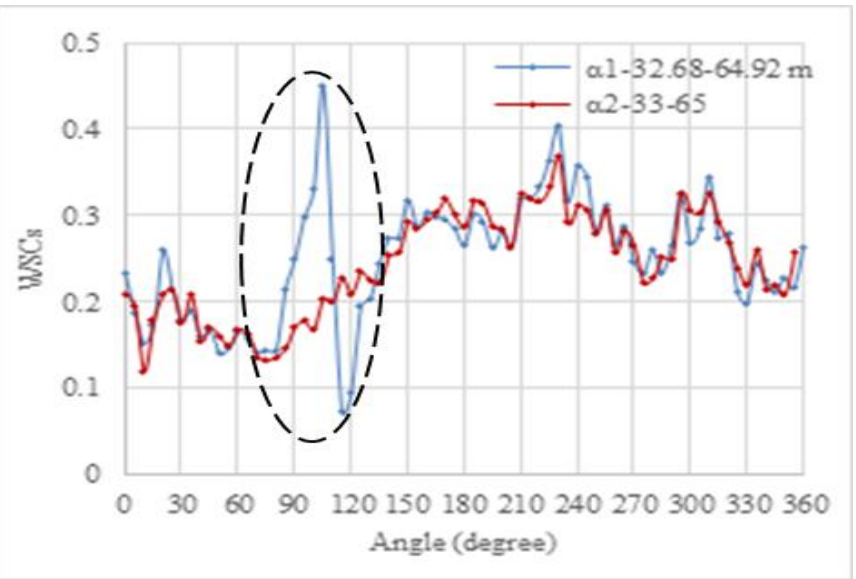

Fig. 5d. Time series WSC calculated for the in-situ $(32.68 \mathrm{~m}$ to $64.92 \mathrm{~m}$ ) and for the LiDAR ( $33 \mathrm{~m}$ to $65 \mathrm{~m}$ ), binned in $5^{\circ}$ wind direction intervals and drawn as a function of the wind direction. 
Similarly, $\alpha 1$ calculated between $16.88 \mathrm{~m}$ and $64.92 \mathrm{~m}$ (in-situ) deviated by $48.60 \%$ when compared with $\alpha 2$ calculated between $17 \mathrm{~m}$ and $65 \mathrm{~m}$ (LiDAR), and $\alpha 1$ and $\alpha 2$ differed by $58.04 \%$ in the peak of the waked region when computed between $16.88 \mathrm{~m}$ and $32.68 \mathrm{~m}$ (in-situ) and $17 \mathrm{~m}$ and $33 \mathrm{~m}$ (LiDAR). Further evaluation reveals a difference of $54.04 \%$ between $\alpha 1$ and $\alpha 2$ in the peak of the waked region following computation of WSC from $32.68 \mathrm{~m}$ to $64.92 \mathrm{~m}$ (in-situ) and from $33 \mathrm{~m}$ to $65 \mathrm{~m}$ (LiDAR).

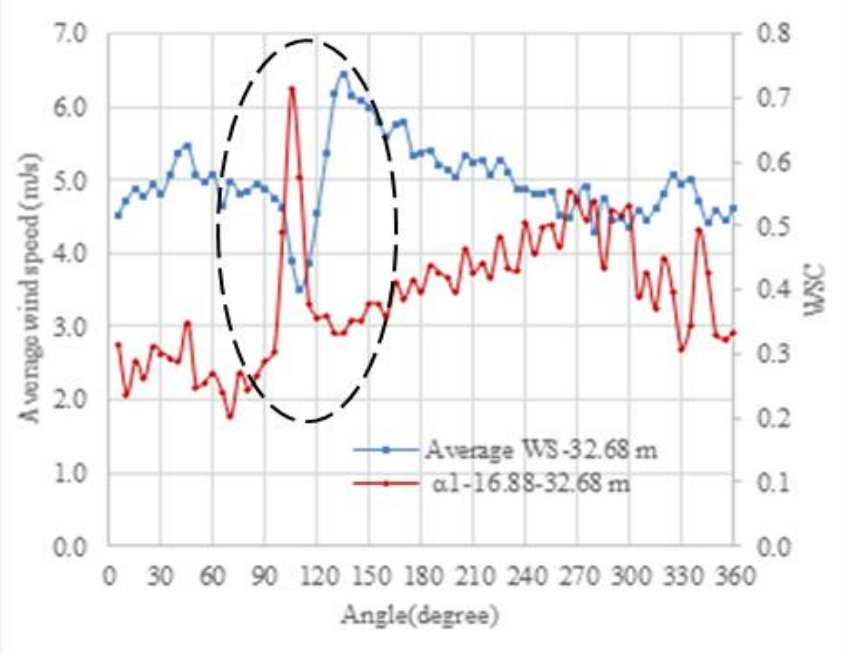

Fig. 6a. Relationship between WS5 and WSC at $32.68 \mathrm{~m}$ (insitu) measurement at Amper-bo.

Fig. 6a and Fig. 6b illustrate the relatedness of WSC and average wind speed at $32.68 \mathrm{~m}$ (in-situ) and $33 \mathrm{~m}$ (LiDAR) respectively. The two parameters were binned in $5^{\circ}$ bins of wind direction intervals. The tower affected sectors (the dashed oval circle) show that a reduction in mean wind speed led to an increase in WSC values. Such abrupt change in the WSC pattern (which occurred consistently at approximately the same angle range with the wind speeds captured using anemometers mounted on the tower) is not noticed in the in the undisturbed LiDAR observed wind data.

Similar analysis performed using data obtained from the Schlip experiment clearly defined the sectors affected by tower shading. The two parameters evaluated (speed ratio and WSC) were binned in $5^{\circ}$ bins of wind direction intervals and drawn as a function of the wind direction captured by the in-situ measurements (Fig. 7a and Fig. 7b). The traditional speed ratios (WS8/sLWS2) and (WS9/sLWS4) clearly define the wake boundaries in the affected direction sectors. The affected angle range was approximately $70^{\circ}$, shown in Fig. 7a by the dotted oval shape. Again, time series WSC computed and drawn as a function of the wind direction using WS8 and WS9, located at approximately the same azimuth angle $\left(160^{\circ}\right)$ from the north accurately predicted the waked boundaries, characterized with abrupt change in the WSC pattern. As with

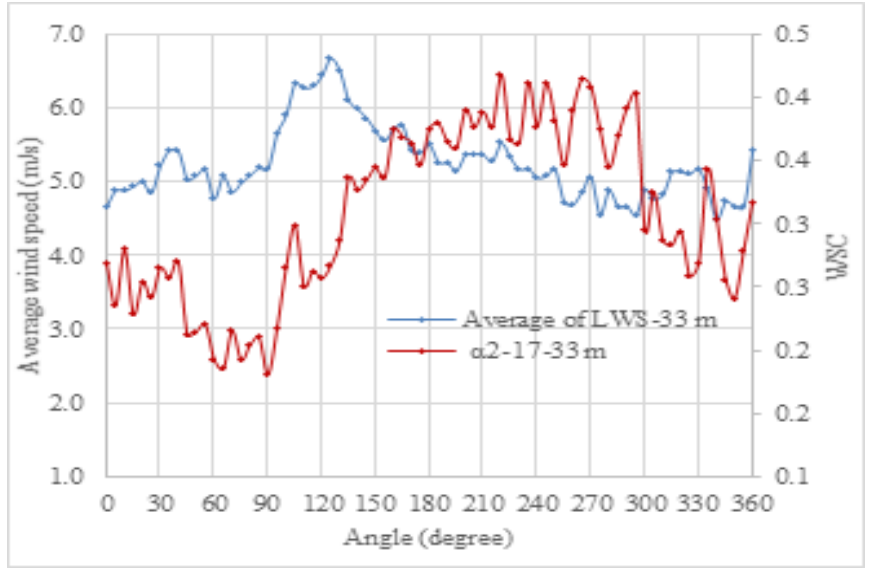

Fig. 6b. Relationship between LWS3 and WSC at $33 \mathrm{~m}$ (LiDAR) measurement at Amber-bo.

the speed ratio approach, the WSC approach captured the affected angle range of approximately $70^{\circ}$, shown in Fig. $7 \mathrm{~b}$ by the dotted oval shape. Both approaches correctly showed that the most severely affected sectors were between $285^{\circ}$ and $290^{\circ}$. The speed deficits at $20.63 \mathrm{~m}$ and $49.9 \mathrm{~m}$ when compared with LiDAR measurement were $23.04 \%$ and $37.62 \%$ respectively. The regions indicated by the dotted rectangles in Fig. 7 were characterized by speed reduction and marked variation in the WSC. Further reduction in speed encountered by the in-situ measurements (WS8 and WS9) in this region may be traceable to the boom influence or perturbations due to the presence of some secondary support structures, since there were no other sheltering obstacles within the vicinity of the experiment. It is again established that time series WSC computed from wind data measured at two different heights and the same azimuth from the north could be used for identifying the wake affected sectors without the need for a collocated sensor.

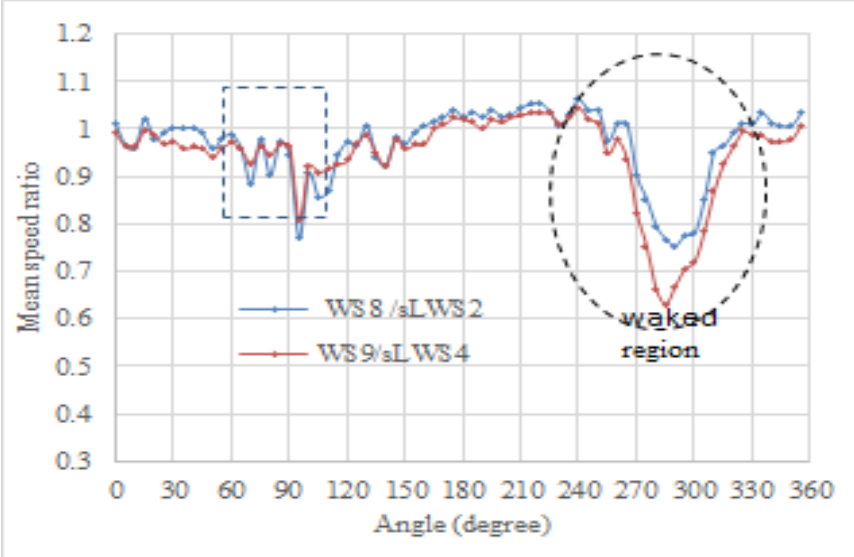

Fig.7a. Ratio of WS8 and sLWS2 and WS9 and sLWS4 plotted on sector-wise basis and binned in $5^{\circ}$ wind direction intervals. The oval and rectangular dashed shapes indicate the wake affected direction at Schlip in the course of three months data captured concurrently in 2014 . 


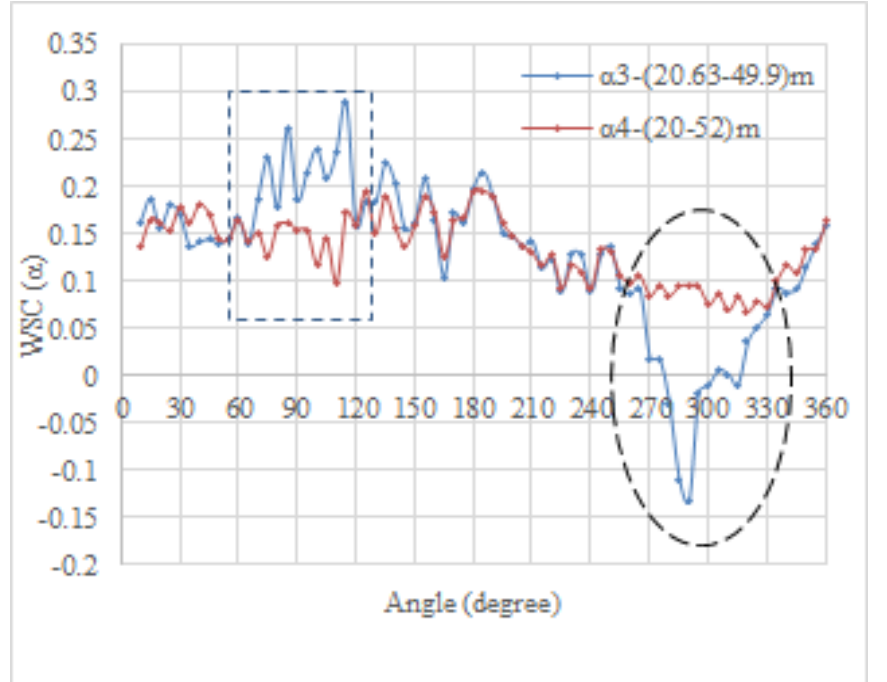

Fig. 7b. Time series WSC calculated for the in-situ $(20.63 \mathrm{~m}$ to $49.9 \mathrm{~m})$ and for the LiDAR $(20 \mathrm{~m}$ to $52 \mathrm{~m})$, binned in $5^{\circ}$ wind direction intervals. The oval and rectangular dashed shapes indicate the wake affected direction at Schlip in the course of three months data captured concurrently in 2014.

\section{WEIBULL AND WIND POWER DENSITY (WPD): TOWER WAKE DISTORTION CHARACTERIZATION}

The two parameter Weibull distribution has been used extensively to describe wind speed variation commonly encountered in the majority of wind assessment projects. However, the Weibull distribution has a limitation in that it does not reveal good conformity for low wind speeds, which is a problem because tower wake distortion is characterized by low wind speed. It becomes interesting to verify how Weibull two parameter functions describe the direction sectors affected by tower shadowing if such sectors were not excluded before analysis.

Time series wind speeds at both sites were binned into $10^{\circ}$ wind direction intervals. At Amper-bo, the collocated sensors at $16.88 \mathrm{~m}$ were used whereas at Schlip the in-situ measurement at $49.9 \mathrm{~m}$ and the LiDAR captured data at $52 \mathrm{~m}$ were used. The Weibull k, c, and WPD were calculated over $36^{\circ}$ wind direction sectors. The probability density function $\mathrm{f}(\mathrm{v})$ and cumulative distribution $\mathrm{F}(\mathrm{v})$ were also evaluated.

Fig. 8 illustrates the variation of the Weibull shape factor $k$ with wind direction sectors. At Schlip, the $\mathrm{k}$ values obtained from both anemometer and LiDAR have the same pattern (Fig 8a). The mean values of $\mathrm{k}$ are 2.38 and 2.67 for WS9 and sLWS4 respectively. At Amper-bo, the $\mathrm{k}$ values calculated from the collocated sensors show the same pattern (Fig. 8b). The mean $\mathrm{k}$ values for the collocated sensors are 2.27 for WS4 and 2.37 for WS4B. The $\mathrm{k}$ values recorded in each $10^{\circ}$ wind direction bin depends on the spread of wind speed. Tower shading has no noticeable effect on the k values calculated.

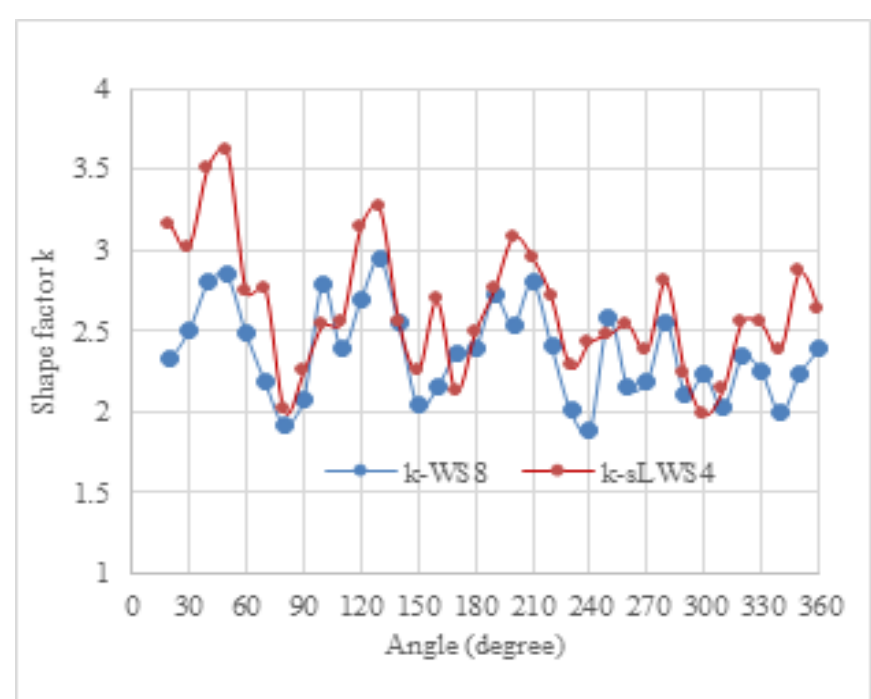

Fig.8a. Weibull $\mathrm{k}$ for in-situ (WS9) and LiDAR (WS4) binned in $10^{\circ}$ wind direction intervals and drawn as a function of the wind direction at Schip.

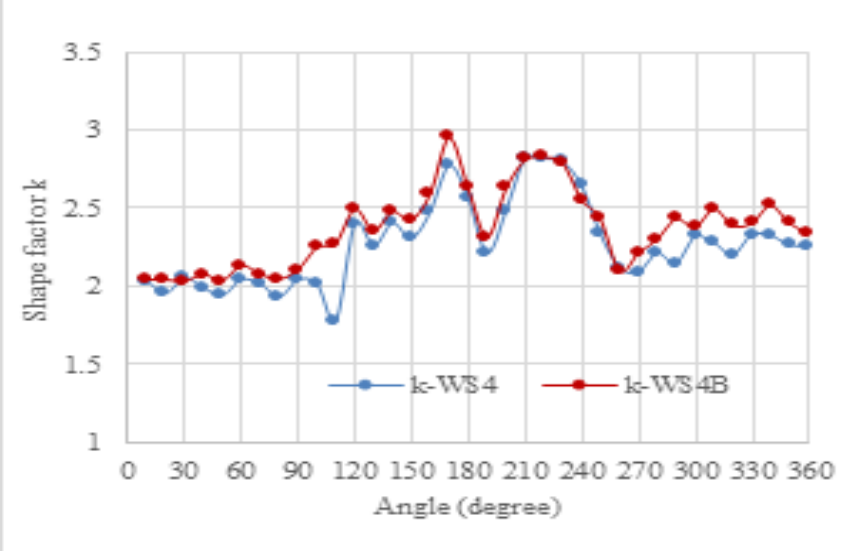

Fig. 8b. Weibull k for in-situ (WS4) and (WS4B) binned in $10^{\circ}$ wind direction intervals and drawn as a function of the wind direction at Amper-bo.

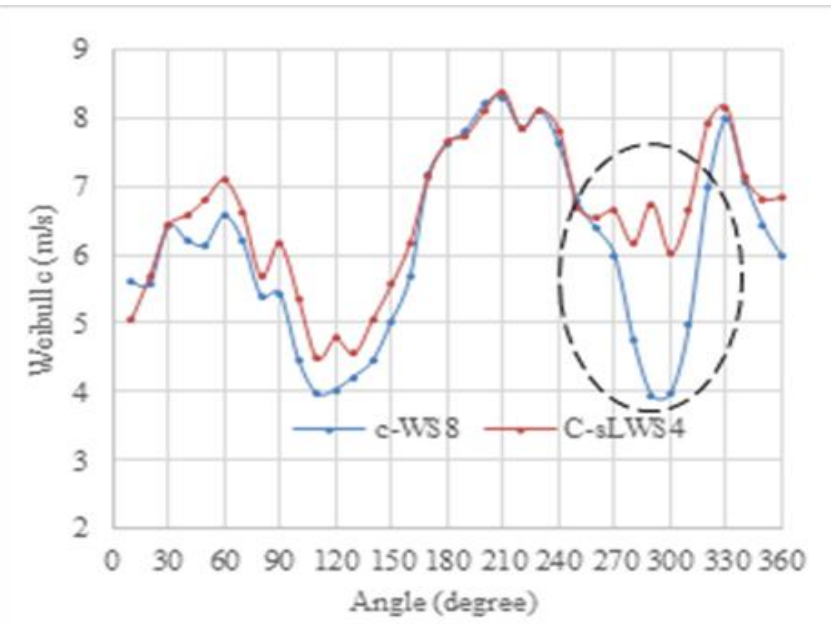

Fig. 8c. Weibull c for the in-situ (WS9) and LiDAR (sLWS4) binned in $10^{\circ}$ wind direction intervals and drawn as a function of the wind direction at Schip. 


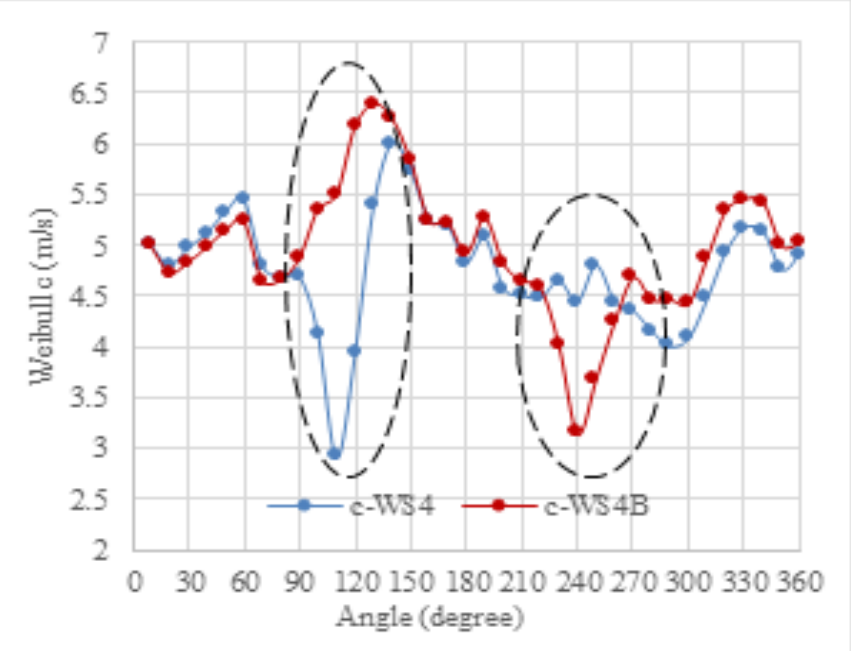

Fig. 8d. Weibull c for the collocated sensors (WS4 and WS4B) binned in $10^{\circ}$ wind direction intervals and drawn as a function of the wind direction at Amper-bo.

Fig. 8a and Fig. 8c are the Weibull scale factor (c) which indicates how windy a site is. The parameter is affected by tower induced flow perturbations as indicated with the oval dashed circle. At Schlip, the overall average of c ws $6.09 \mathrm{~m} / \mathrm{s}$ which was $12.17 \%$ higher than the observed average of WS9. The mean value of c computed from the LiDAR (sLWS4) captured data was $6.59 \mathrm{~m} / \mathrm{s}$ which was $13.72 \%$ higher than the sLWS4 average. Based on the $10^{\circ}$ bin of wind direction intervals used, the sector that was most severely affected by tower induce flow perturbations was $290^{\circ}$. A speed deficit of $37.84 \%$ resulted in a corresponding $41.65 \%$ deficit of Weibull c when the LiDAR (sLWS4) observed data was compared with WS9. Similarly, at Amper-bo, the average of c generated from WS4 was $4.75 \mathrm{~m} / \mathrm{s}$ which was $12.99 \%$ higher than the mean of WS4. The same was applicable to WS4B where the mean $\mathrm{c}$ value $(4.96 \mathrm{~m} / \mathrm{s})$ was $13.49 \%$ of WS4B mean.

The most severely affected sectors by tower shading were $110^{\circ}$ and $240^{\circ}$ for WS4 and WS4B respectively. At $110^{\circ}$, WS4 was $44.96 \%$ less than WS4B and c of WS4 was $46.99 \%$ less than c of WS4B. At $240^{\circ}$, WS4B was $32.22 \%$ less than WS4 and c of WS4B was $29.19 \%$ less than c of WS4. The discrepancies in the severity revealed that WS4 was more exposed to the tower shadings than WS4B. Based on the results from the two sites, this study may conclude that the mean values of Weibull c were between $12 \%$ to $14 \%$ higher than the observed mean speed at these two locations.

The probability density function, cumulative frequency, and frequency of occurrence of the observed speed in the severely affected direction sectors are illustrated in Fig.9a to Fig. 9d.

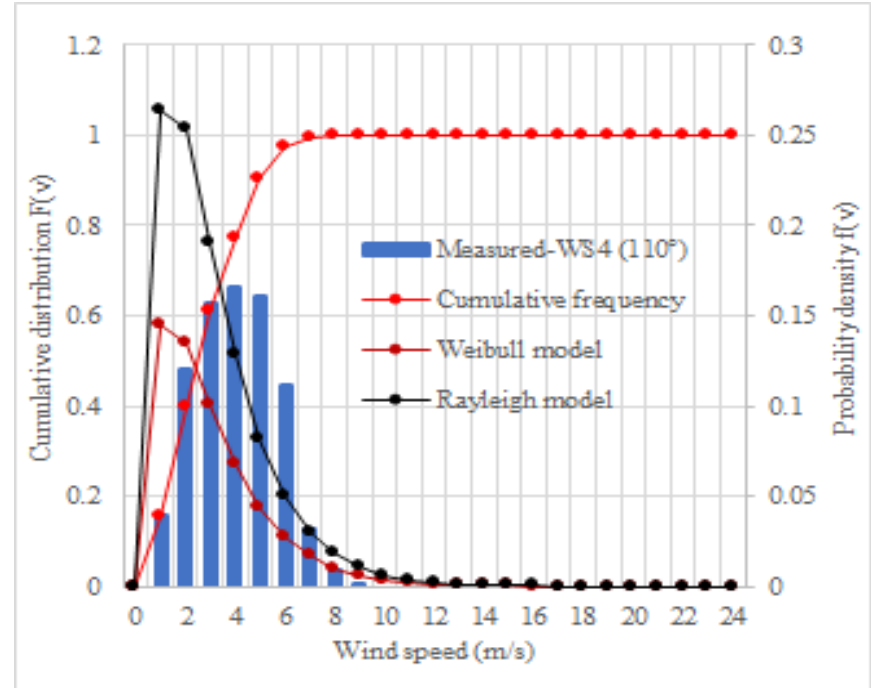

Fig. 9a. Wind speed probability density, cumulative frequency and observed frequency of WS4 obtained from the most severely affected direction sector $\left(110^{\circ}\right)$ at Amper-bo.

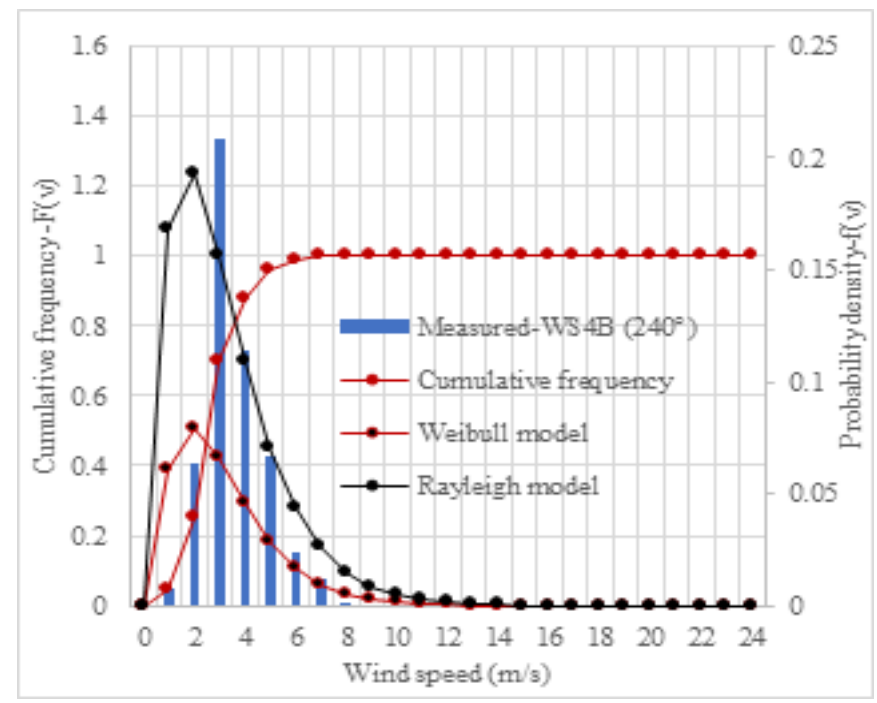

Fig.9b. Wind speed probability density, cumulative frequency and observed frequency of WS4B obtained from the most severely affected direction sector $\left(240^{\circ}\right)$ at Amper-bo.

Fig. 9d is the direction sector where the collocated sensors at Amper-bo were both out of tower wake effect. The direction sectors severely affected were characterized mostly by lower wind speeds and lower spread as well. The distribution models (Weibull and Rayleigh) used demonstrate a measure of weakness, hence, the notable under-prediction of resource parameters evaluated from such direction sector (Fig. 9a, Fig. $9 \mathrm{~b}$ and Fig. 9c). Further statistics would reveal the most suitable of the two in characterizing resource parameters at both sites. 


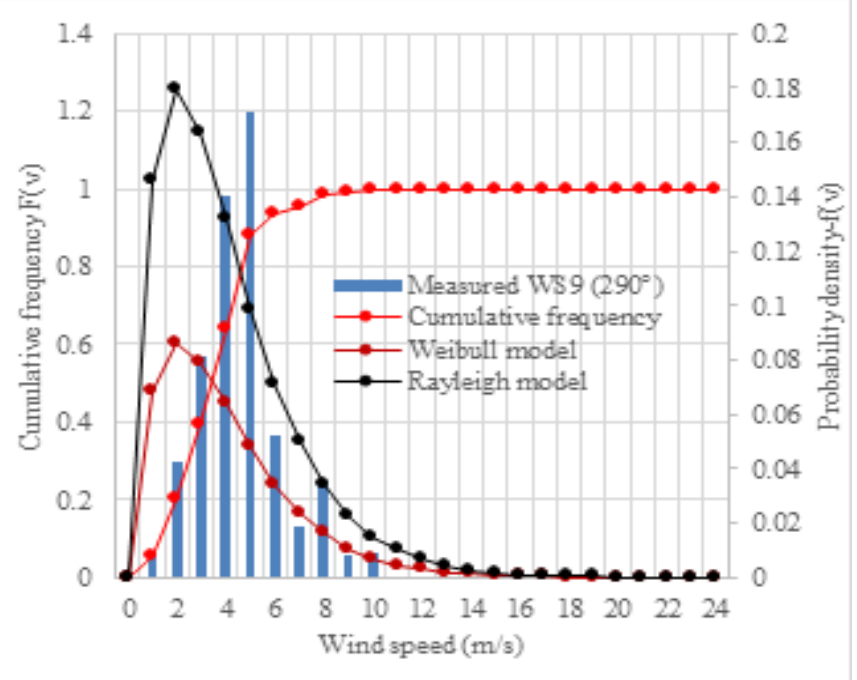

Fig. 9c. Wind speed probability density, cumulative frequency and observed frequency of WS49 obtained from the most severely affected direction sector $\left(290^{\circ}\right)$ at Schlip.

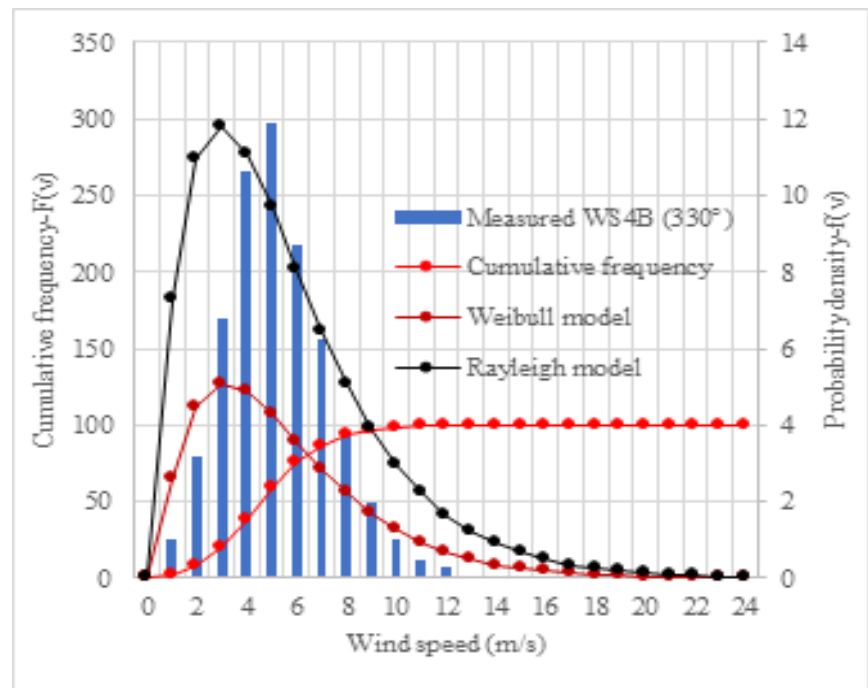

Fig. 9d. Wind speed probability density, cumulative frequency and observed frequency of WS4B obtained from udisturebed direction direction sector $\left(330^{\circ}\right)$ at Amper-bo.

The WPD computed from each $10^{\circ}$ bin of the observed (WS4 and WS4B) probability density distributions and the corresponding values obtained from the Weibull and Rayleigh models and the associated errors based on the two models are illustrated in Fig 10. The dashed oval shape represents the direction sectors under the influence of the tower wakes. The sector-wise comparison of the WPD (Fig. 10a and Fig. 10c) affirms that WPD depends on site observed wind speed, with higher values in the direction sectors that are windier.

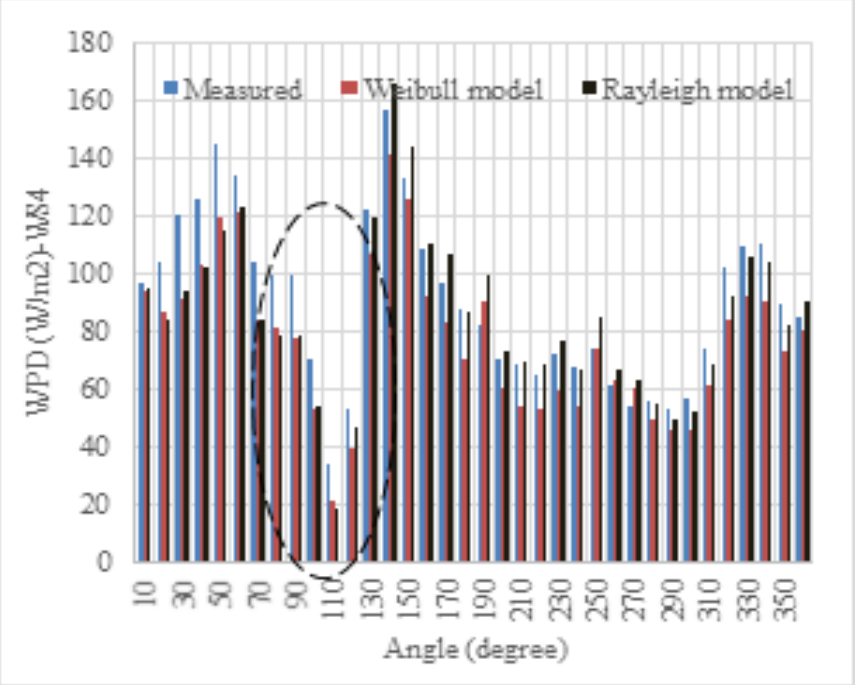

Fig. 10a. WPD of the observed (WS4) compared to those obtained from the Weibull and Rayleigh models at Amper-bo.

Based on the WS4 analysis, the observed average WPD was $90.13 \mathrm{~W} / \mathrm{m}^{2}$. The corresponding values for Weibull and Rayleigh models were $77.36 \mathrm{~W} / \mathrm{m}^{2}$ and $85.48 \mathrm{~W} / \mathrm{m}^{2}$ respectively. These results indicated $14.16 \%$ and $5.16 \%$ underestimation by the Weibull and Rayleigh models respectively. Similarly, the observed average WPD for WS4B was $98.59 \mathrm{~W} / \mathrm{m}^{2}$. The Weibull model yielded $85.41 \mathrm{~W} / \mathrm{m}^{2}$, whereas the Rayleigh model yielded $97.90 \mathrm{~W} / \mathrm{m}^{2}$.

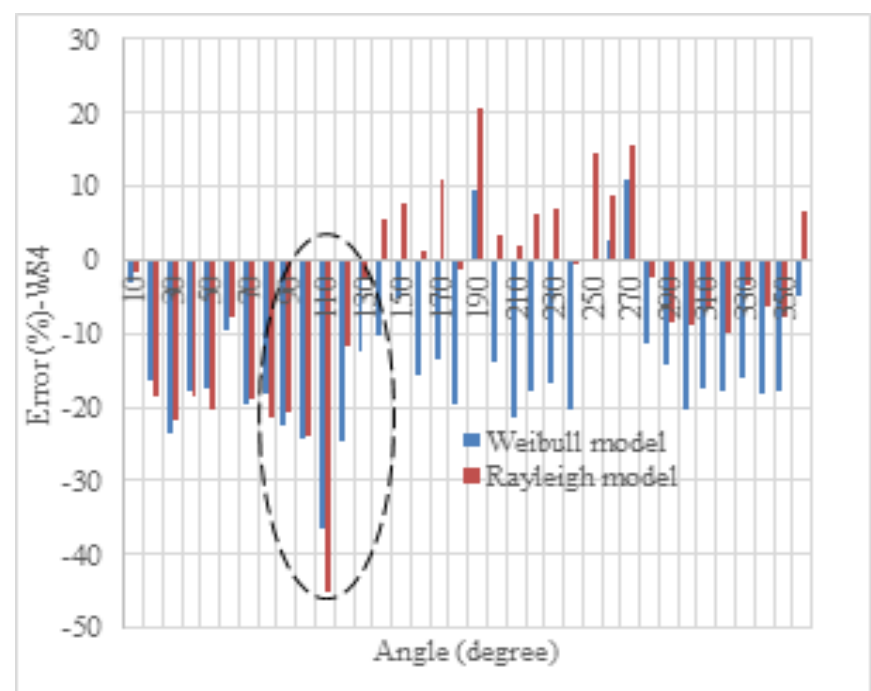

Fig. 10b. WPD values predicted by Weibull and Rayleigh models in reference to the WPD obtained from the observed (WS4) at Amper-bo. 


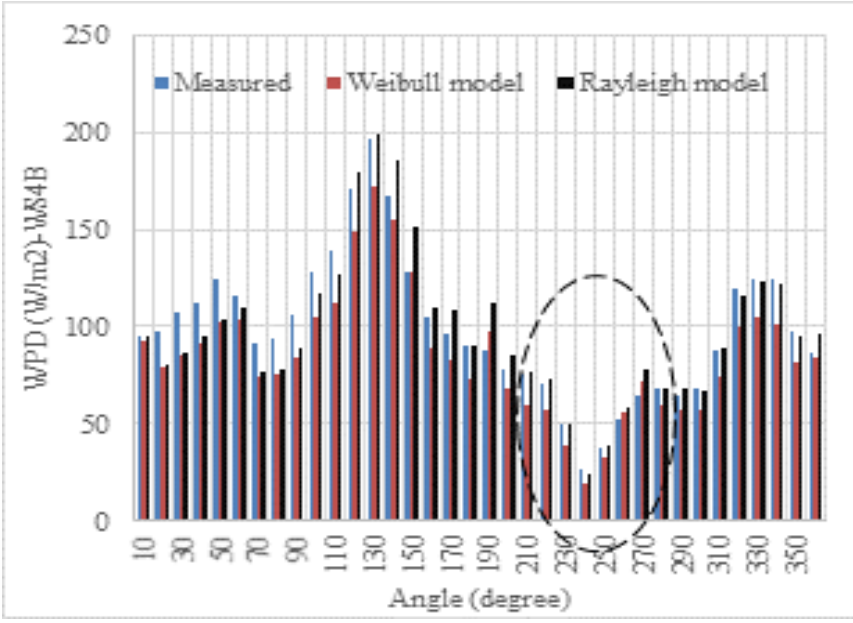

Fig 10c. WPD of the observed (WS4B) compared to those obtained from the Weibull and Rayleigh models at Amper-bo.

The Weibull and the Rayleigh models underpredicted WPD by $13.37 \%$ and $0.70 \%$ respectively. The overall averaging approach, while providing information on the wind power potential of a site, tended to mask the actual characteristics of winds in the direction sectors; hence the sector-wise evaluation. Again, at the WS4 most severely affected sector $\left(110^{\circ}\right)$, the Weibull and Rayleigh models under predicted WPD by 36.61 $\%$ and $45 \%$ (Fig. 10b), whereas at $240^{\circ}$, Weibull and Rayleigh models underpredicted WPD by $26.06 \%$ and $9.5 \%$ respectively (Fig. 11d).

The tower shading impact on WPD was examined by comparing data from the collocated sensors (WS4 and WS4B) at the two most severely affected sectors $110^{\circ}$ and $240^{\circ}$, respectively. At $110^{\circ}$, WPD (measured) of WS4 was $75.4 \%$ less than WPD (measured) of WS4B, and the Weibull and Rayleigh models of WS4 underpredicted WPD by $80.68 \%$ and $85.11 \%$ when compared to their counterparts in WS4B. Also, at $240^{\circ}$, the WPD obtained from WS4B measured data was $60.99 \%$ less than the WPD obtained from WS4.

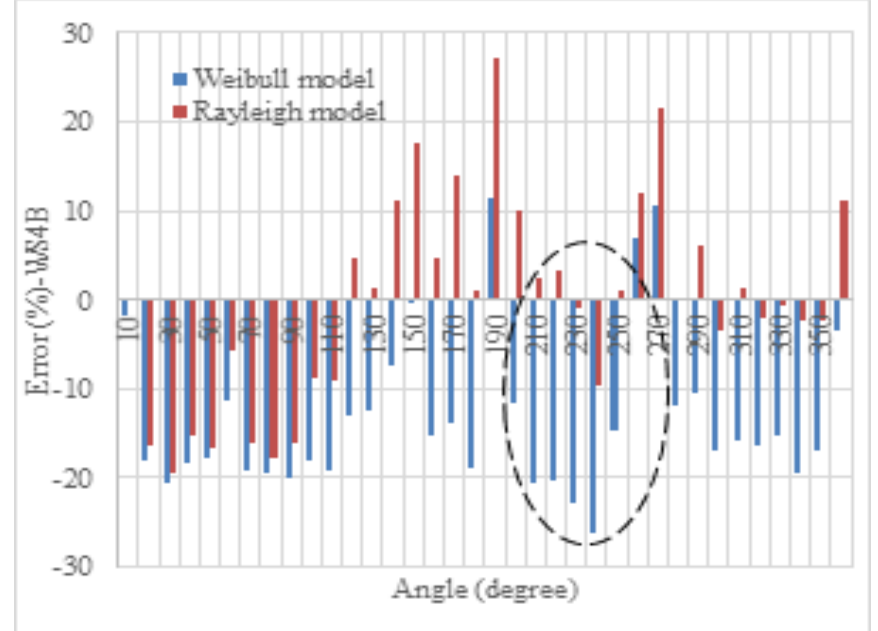

Fig. 10d. WPD values predicted by Weibull and Rayleigh models in reference to the WPD obtained from the observed (WS4B) at Amper-bo.

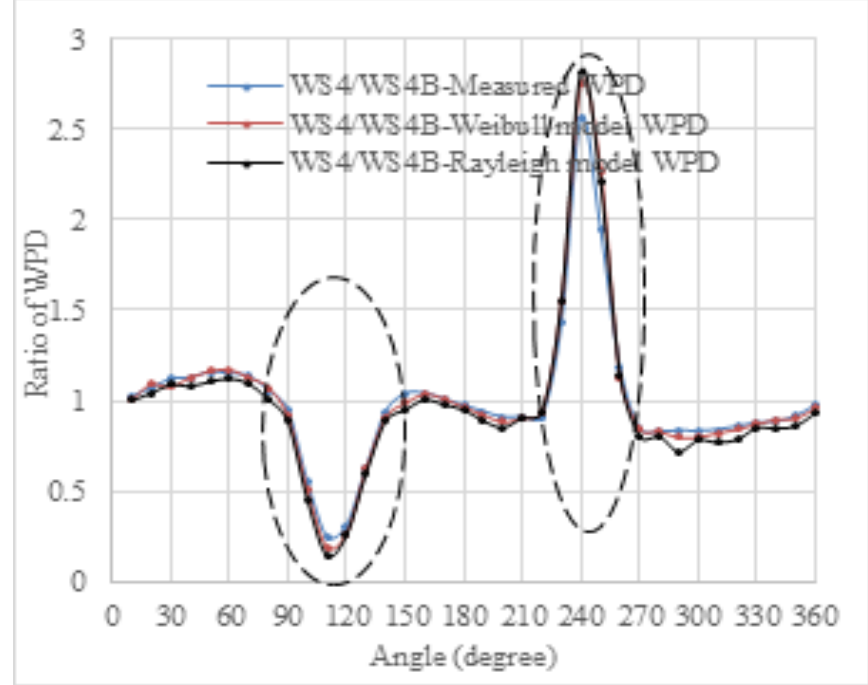

Fig. 11. Ratio of WPD obtained from the observed probability density distribution functions and the corresponding values obtained from the Weibull and Rayleigh models based on the collocated sensors (WS4 and WS4B) at Amper-bo.

The ratios of the WPD obtained from the measured data and from the two models, drawn as a function of the wind direction, are illustrated in Fig. 11. The boundaries of the wake affected regions are defined and indicated by the dashed over shape. The two models captured the waked regions of the two sensors sufficiently. When the affected direction sectors were removed, WS4 saw an improvement of $3.78 \%$ for the WPD obtained from the observed data. WPD from the Weibull and Rayleigh models improved by $4.6 \%$ and $4.87 \%$ respectively. In WS4B, the measured WPD increased by $9.78 \%$. The Weibull and Rayleigh approaches increased by $9.28 \%$ and $9.03 \%$ respectively.

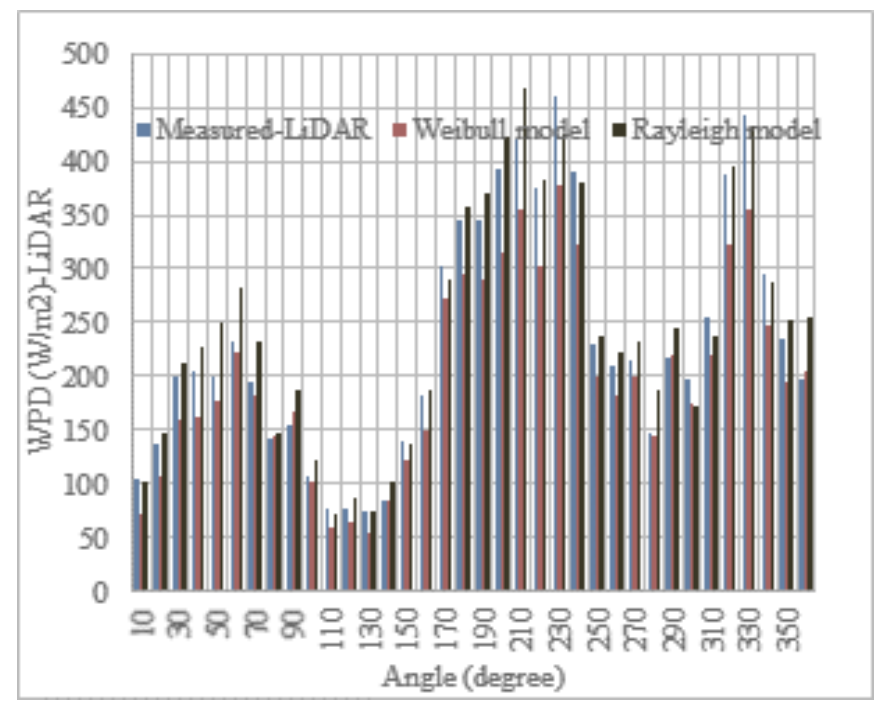

Fig. 12a. WPD of the observed LiDAR (LWS4) compared to those obtained from the Weibull and Rayleigh models at Schlip.

In Schlip, the WPD computed from each $10^{\circ}$ bin of the observed (WS9 and sLWS4) probability density distributions and the corresponding values obtained from the Weibull and Rayleigh models and their associated errors when compared to 
the observed data are illustrated in Fig. 12. The dashed oval shape represents the direction sectors that were under the influence of tower shading (Fig 12a to Fig. 12d). Analysis of WS9 shows that the observed average WPD was $211.18 \mathrm{~W} / \mathrm{m}^{2}$. The corresponding values for Weibull and Rayleigh models were $181 \mathrm{~W} / \mathrm{m}^{2}$ and $206.28 \mathrm{~W} / \mathrm{m}^{2}$ respectively.

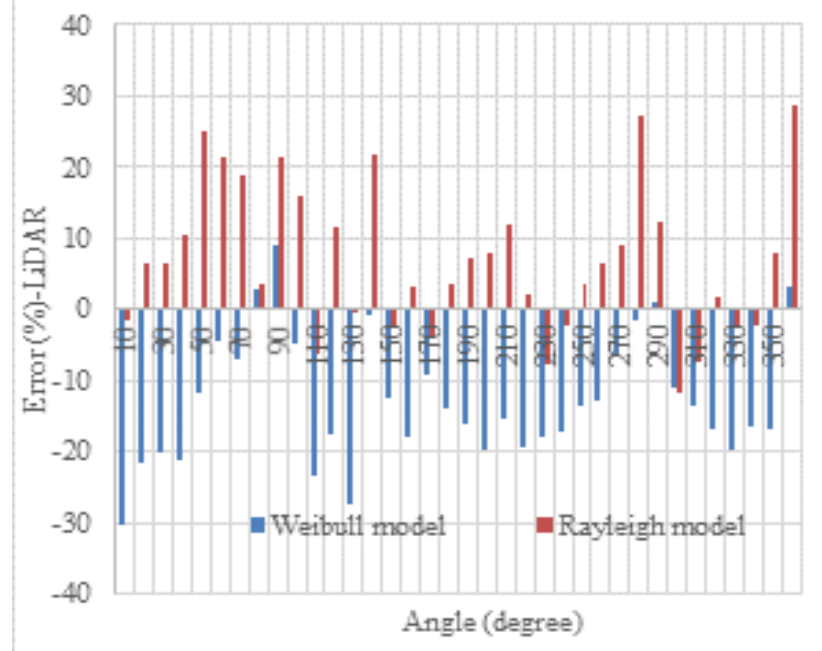

Fig. 12b. WPD values predicted by the Weibull and Raleigh models in reference to the WPD obtained from the observed LiDAR (sLWS4) data at Schlip.

The results represent a $14.29 \%$ and $2.32 \%$ underestimation by the Weibull and Rayleigh models respectively. Similarly, the observed average WPD for the LiDAR (sLWS4) is 232.47 $\mathrm{W} / \mathrm{m}^{2}$. The Weibull model yielded $200.67 \mathrm{~W} / \mathrm{m}^{2}$ and the Rayleigh model yielded $245.16 \mathrm{~W} / \mathrm{m}^{2}$. The Weibull under predicted WPD by $13.68 \%$ while the Rayleigh model overpredicted WPD by $5.46 \% \%$. Based on the sector-wise evaluation, at the WS9 most severely affected sector $\left(290^{\circ}\right)$, the Weibull and Rayleigh models under predicted WPD by $21.50 \%$ and $17.11 \%$ (Fig. 12c). The LiDAR observed data was considered undisturbed; as a result, the influence of tower induced flow perturbation was absent.

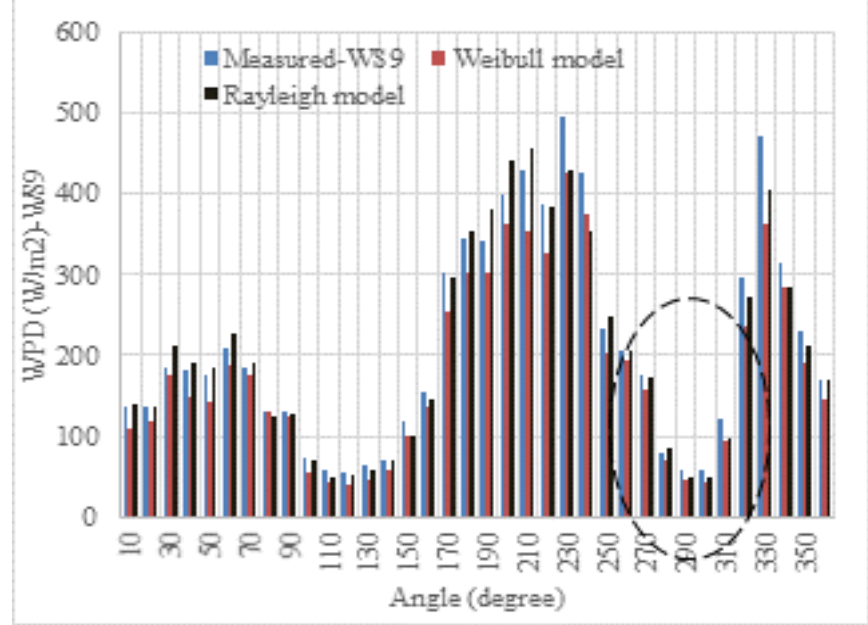

Fig. 12c.WPD of the observed (WS9) compared to those obtained from the Weibull and Rayleigh models at Schlip.
The impact of tower shading on WPD was examined by comparing WS9 and LiDAR (sLWS4) for the three months when the two data acquisition systems concurrently captured wind data. At $290^{\circ}$, the WPD obtained from WS9 was $73.11 \%$ less than the WPD obtained from the measured LiDAR (sLWS4) wind speed. The WPD based on the Weibull and Rayleigh models of WS9 under predicted WPD by $79.09 .68 \%$ and $80.13 \%$ respectively when compared to their counterparts obtained based on LiDAR (sLWS4) valuation. The ratios of the WPD obtained from the measured data and from the two models, drawn as a function of the wind direction (Fig. 13), clearly defined the wake boundaries.

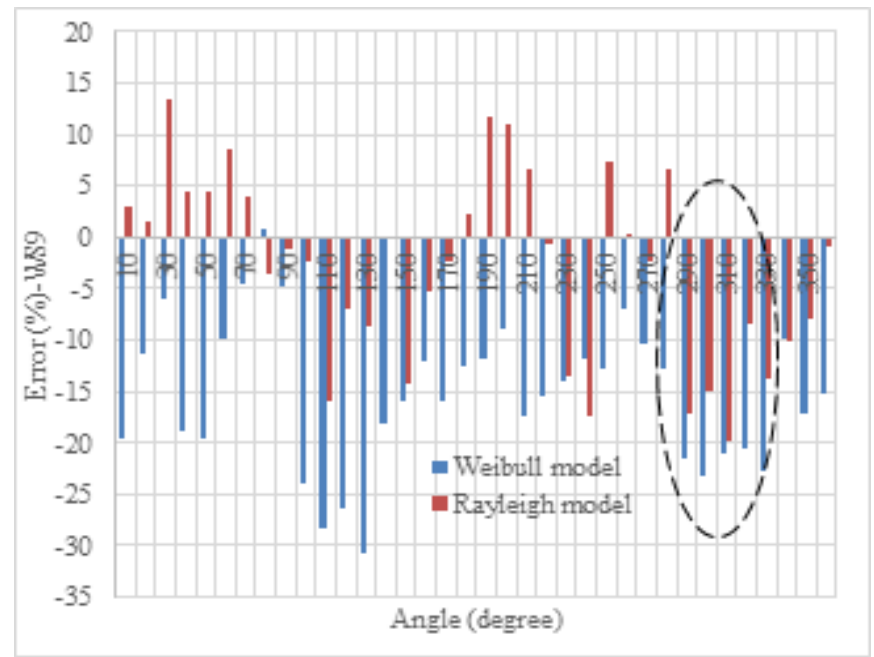

Fig. 12d. WPD values predicted by Weibull and Rayleigh models in reference to the WPD obtained from the observed (WS9) at Schlip.

The two models captured the affected direction sectors sufficiently. When the affected direction sectors were removed, the overall WPD obtained from WS9 improved by $7.79 \%$. The overall WPD from the Weibull and Rayleigh models improved by $8.07 \%$ and $8.24 \%$ respectively.

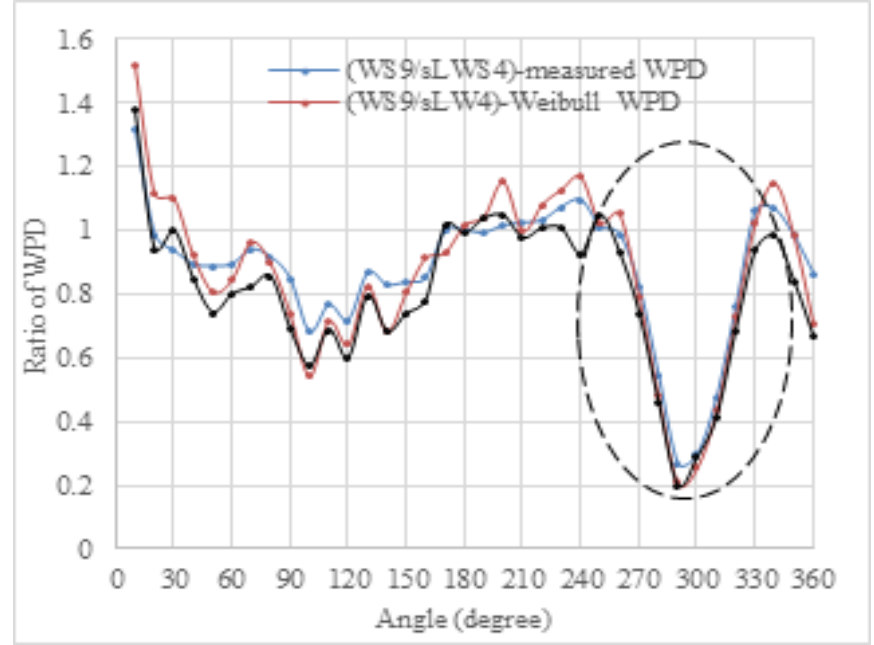

Fig. 13. Ratio of WPD obtained from observed probability density distribution functions and the corresponding values obtained from the Weibull and Rayleigh models based on insitu (WS9)and LiDAR (sLWS4) that were concurrently captured at Schlip. 


\section{TEST-OF-FIT USED}

The measure of goodness-of-fit of the two statistical models (Weibull and Rayleigh) summarizes the differences between the observed values and the values predicted by the models.
The suitability of the models in reference to the observed was determined from the two most applied tests - the root mean square error (RMSE) and the coefficient of determination $\left(\mathrm{R}^{\wedge} 2\right)$. Table VI is a summary the test-of-fit for the distributions (Weibull and Rayleigh) used.

TABLE VI. TEST-OF-FIT FOR WEIBULL AND RAYLEIGH MODELS

\begin{tabular}{|l|l|l|l|l|}
\hline Amper-bo & Weibull (RMSE) & Rayleigh (RMSE) & Weibull $\left(\boldsymbol{R}^{2}\right)$ & Rayleigh $\left(\boldsymbol{R}^{2}\right)$ \\
\hline & 90.37 & 74.60 & 0.9262 & 0.8428 \\
\hline WS4 & 95.65 & 68.38 & 0.9445 & 0.9062 \\
\hline WS4B & Schlip & 152.70 & 0.9882 & 0.9621 \\
\hline WS9 & 244.82 & 148.84 & 0.9735 & 0.9627 \\
\hline sLWS4 & 248.08 & &
\end{tabular}

$\left(\mathrm{R}^{2}\right)$ values close to 1 indicate a strong relation between the model values and the observed values. The Weibull model showed a stronger relation than its counterpart (Rayleigh model) but the $\left(\mathrm{R}^{2}\right)$ values accounted for only the proportion of the variability explained by the observed data. From the tests (Table VI), the scatter index (SI = RMSE/data mean) of less than one indicates that both models sufficiently describe the observed data set. However, the Rayleigh model returned less error (RMSE), making it the most suitable model of the two for both sites.

\section{CONCLUSION}

The wind data analyzed, compared and reported in this study were 10-minute averaged, concurrently observed measurements, using LiDAR and instrumented communication towers in 2014, at Amper-bo and Schlip, two inland locations in southern and central Namibia respectively. At Amper-bo the LiDAR operated for 8.4 months (16 ${ }^{\text {th }}$ Jan. 2014 to $30^{\text {th }}$ Sept. 2014) and nearly 3 months at Schlip ( $31^{\text {st }}$ Sept. 2014 to $24^{\text {th }}$ Dec. 2014) where wind data was measured simultaneously at the instrumented lattice triangular communication towers. The in-situ captured data were evaluated in reference to the LiDAR observed to gain insight into the performance implications of not excluding tower waked regions before analysis. Beside traditional speed ratio which is commonly used, and the coefficient of determination $\left(\mathrm{R}^{2}\right)$ of turbulent kinetic energy (TKE), and turbulence intensity (TI) of collocated sensors recently proposed, this work suggests a simpler approach to identify tower waked direction sectors where collocated sensors are not available but wind data are collected from two intermediate heights with the same azimuth angle from the north.

The following conclusions based on the specific impact of the tower wake distortion on the in-situ observed data verified by the undisturbed LiDAR observations have been drawn:

- Times series WSC computed, binned in $5^{\circ}$ in wind direction intervals and drawn as a function of the wind direction enables the identification and definition of the boundaries of tower waked regions where collocated sensors are not available but wind data are collected from two intermediate heights with the same azimuth angle from the north. The traditional speed ratio approach and the coefficient of determination $\left(\mathrm{R}^{2}\right)$ of turbulence intensity (TI) at Amper-bo for the collocated sensors revealed wake boundaries that cover an angle of approximately $60^{\circ}$. Time series WSC computed between the heights $8 \mathrm{~m}$ to $16.88 \mathrm{~m}, 16.88 \mathrm{~m}$ to $32.68 \mathrm{~m}, 16.88$ $\mathrm{m}$ to $64.92 \mathrm{~m}$ and $32.68 \mathrm{~m}$ to $64.92 \mathrm{~m}$ equally defined wake boundaries covering angles of approximately $60^{\circ}$ when compared with time series WSC calculated using undisturbed LiDAR data at corresponding height intervals. Based on the height intervals previously mentioned, at the most severely affected direction sector $\left(110^{\circ}\right)$, the WSC obtained deviated by $57.0 \%, 58.04 \%, 48.60 \%$ and $54.04 \%$ respectively from their LiDAR counterparts. At Schlip, time series WSC calculated between $20.63 \mathrm{~m}$ and $49.9 \mathrm{~m}$ defined a wake boundary of approximately $70^{\circ}$ when compared with the same evaluation from LiDAR data at the corresponding height interval and the result is again supported by the traditional speed ratio approach which defined a wake boundary of approximately $70^{\circ}$. From this study, it is established that time series WSC computed from wind data measured at two different intermediated heights, located at approximately the same azimuth from the north is sufficient for identifying the wake affected sectors without the need for collocated sensors.

- The two statistical models (Weibull and Rayleigh) demonstrated a measure of weakness in properly characterizing the wake affected zones. Tower shading has no noticeable effect on the $\mathrm{k}$ values calculated on the average from the two sites. Results from the two sites revealed that mean values of Weibull c were between $12 \%$ to $14 \%$ higher than the observed mean speed at these two locations.

- The impact of tower shadow on performance was further verified by the following comparisons: Using the collocated sensors at Amper-bo, at $110^{\circ}$ (WS4 servery affected direction sector), WPD (measured) of WS4 was $75.4 \%$ less than WPD (measured) of WS4B and the Weibull and Rayleigh models of 
International Journal of Engineering Research and Technology. ISSN 0974-3154, Volume 13, Number 11 (2020), pp. $3125-3144$

(C) International Research Publication House. https://dx.doi.org/10.37624/IJERT/13.11.2020.3125-3144

WS4 underpredicts WPD by $80.68 \%$ and $85.11 \%$ when compared to their counterparts in WS4B. Also, at $240^{\circ}$ (WS4B most servery affected direction sector), WPD obtained from WS4B measured data was $60.99 \%$ less than WPD obtained from WS4. When the affected direction sectors were removed, WS4 saw an improvement of $3.78 \%$ for the WPD obtained from the observed data. WPD from the Weibull and Rayleigh models improved by $4.6 \%$ and $4.87 \%$ respectively. In WS4B, the measured WPD increased by $9.78 \%$. The Weibull and Rayleigh approaches increased by $9.28 \%$ and $9.03 \%$ respectively. Using WS9 and LiDAR (sLWS4) at Schlip, at $290^{\circ}$ (WS9) most severely affected direction sector), the WPD obtained from WS9 was $73.11 \%$ less than WPD obtained from the measured LiDAR (sLWS4) wind speed. The WPD based on the Weibull and Rayleigh models of WS9 under predicted WPD by $79.09 .68 \%$ and $80.13 \%$ respectively when compared to the results of their counterparts based on LiDAR (sLWS4) valuation. When the affected direction sectors were removed, the overall WPD obtained from WS9 improved by $7.79 \%$. The overall WPD from the Weibull and Rayleigh models improved by $8.07 \%$ and $8.24 \%$ respectively.

- Regarding data availability at both sites, there was a $100 \%$ data recovery rate (in-situ) and a consistent data recovery at all heights $>95 \%$ (LiDAR), except the three topmost heights where the data availability fell below that. This trend is attributed to weak backscatter signal which is difficult for the LiDAR to detect due to large beam waist radius and measurement probe depth at such heights.

- The wind roses at both sites were thoroughly described and insights gained on the direction sectors where predominant and strongest winds blow. The direction sectors affected by tower shadings at both sites were characterized with disproportionally higher percentages of low wind regimes compared to other sectors and this was contrary to the LiDAR observation within those affected sectors.

- Various models were explored to compute WSC to permit hub height extrapolations and revealed that the magnitude depends on the model applied. On the monthly variation of WSC for both measurement techniques at the two sites, the winter months (May, June and July) accounted for the highest values whereas the summer months (January and December) recorded the least values. The same applied to the monthly variations of the roughness lengths. This trend is due to thermal stratification of the atmospheric body at both sites. Diurnally, the computed WSC at both Amber-bo and Schlip showed evidence of direct correlation to the diurnal heating/cooling cycle of air above the ground, and thus of atmospheric stability. Higher values were recorded in the stable night hours whereas the unstable daylight hours accounted for the lowest values. The same applied to the diurnal variation of roughness length.

Thus, tower shading impact on resource parameters have been examined. From this study, it is established that time series WSC computed from wind data measured at two different intermediate heights, located at approximately the same azimuth from the north can be used for identifying the wake affected sectors without the need for collocated sensors. Regarding the performance implications, failure to address tower distortion effect properly will lead to underpredictions of energy yield. Further statistical review shows that the Rayleigh model performed better than the Weibull model at both sites.

\section{ACKNOWLEDGMENT}

Funding for this project was provided by the Ministry of Foreign Affairs of Denmark, Ministry of Foreign Affairs of Finland, United Kingdom Department for International Development, Austrian Development Agency and Namibia Power Corporation. Invaluable support is provided by Namibia Energy Institute under Namibia University of Science and Technology.

\section{REFERENCES}

[1] M. Sanuki, S. Kimura, and S. Toyama, "Anemometer reading in the presence of nearby obstacle," Pap. Meteorol. Geophys., vol. 6, pp. 140-143, Jan. 1955, doi: 10.2467/mripapers1950.6.2_140.

[2] M. E. Okorie and F. Inambao, "Identification of tower and boom-wakes using collocated anemometers and lidar measurement," Int. J. Mech. Eng. Technol., vol. 10, no. 06, pp. 72-94, 2019.

[3] M. E. Okorie and F. Inambao, "Identification of towerwake distortion using LiDAR measurement," Procedia Manuf., vol. 35, pp. 704-710, 2019, doi: 10.1016/j.promfg.2019.06.012.

[4] S. Fabre, M. Stickland, T. Scanlon, A. Oldroyd, D. Kindler, and F. Quail, "Measurement and simulation of the flow field around the FINO 3 triangular lattice meteorological mast," J. Wind Eng. Ind. Aerodyn., vol. 130, pp. 99-107, Jul. 2014, doi: 10.1016/j.jweia.2014.04.002.

[5] M. Stickland, T. Scanlon, S. Fabre, A. Oldroyd, and D. Kindler, "Measurement and simulation of the flow field around a triangular lattice meteorological mast," Energy Power Eng., vol. 5, Oct. 2013.

[6] R. N. Farrugia and T. Sant, "Modelling wind speeds for cup anemometers mounted on opposite sides of a lattice tower: a case study," J. Wind Eng. Ind. Aerodyn., vol. 115, pp. 173-183, 2013, doi: 10.1016/j.jweia.2012.11.006. Meteorol. Mag., vol. 89, pp. 209-215.

[7] N. E. Rider, "On the performance of sensitive cup anemometers," Meteorol. Mag., vol. 89, pp. 209-215. 1960.

[8] B. Maribo Pedersen, K. S. Hansen, S. Øye, M. Brinch, and O. Febian, "Some experimental investigations on the influence of the mounting arrangements on teh accuracy of cup-anemometer measurements," J. Wind Eng. Ind. Aerodyn., vol. 39, no. 1, pp. 373-383, Jan. 1992, doi: 10.1016/0167-6105(92)90561-N.

[9] J. E. Cermak and J. D. Horn, "Tower shadow effect," J. Geophys. Res., vol. 73, no. 6, pp. 1968, doi: 10.1029/JB073i006p01869. 
International Journal of Engineering Research and Technology. ISSN 0974-3154, Volume 13, Number 11 (2020), pp. 3125-3144

(C) International Research Publication House. https://dx.doi.org/10.37624/IJERT/13.11.2020.3125-3144

[10] W. F. Dabberdt, "Tower-induced errors in wind profile measurements," J. Appl. Meteorol., vol. 7, no. 3, pp. 359-366, 1968.

[11] N. Nishio et al., "A study on wind speed correction method of lattice tower mast using CFD simulation," Transactions of the JSME (in Japanese), vol. 84, no. 862, pp. 18-00042-18-00042, 2018, doi: $10.1299 /$ transjsme.18-00042.

[12] M. Tusch, C. Masson, and P. Héraud, "Modeling of turbulent atmospheric flow around tubular and lattice meteorological masts," J. Sol. Energy Eng, vol. 133, no. 1, p. 011011, Feb. 2011, doi: 10.1115/1.4003293.

[13] V. Bezrukovs, V. Bezrukovs, S. Upnere, L. Gulbe, and D. Bezrukovs, "The use of cellular communication masts for wind share research," Energetika, vol. 64, no. 2, Sep. 2018, doi: 10.6001/energetika. v64i2.3780.

[14] M. Lotfi, “Atmospheric Wind Flow Distortion Effects of Meteorological Masts," Annual Conference of the Portuguese Renewable Energy Association (APREN), Lisbon, Portugal, 2016. DOI: 10.13140/RG.2.2.36519.39848

[15] K. McCaffrey et al., "Identification of tower-wake distortions using sonic anemometer and lidar measurements,"Atmos. Meas. Tech., vol. 10, no. 2, pp. 393-407, 2017, doi: http://dx.doi.org/10.5194/amt-10393-2017.

[16] International Electrotechnical Commission (IEC), "Wind energy generation systems - Part 12-1: Power performance measurements of electricity producing wind turbines," International Electrotechnical Commission (IEC), IEC Central Office 3 rue de Varembé CH-1211 Geneva 20, Switzerland, International Standard IEC 61400-12-1:2005(E), Dec. 2005.

[17] International Electrotechnical Commission (IEC), "Wind energy generation systems - Part 12-1: Power performance measurements of electricity producing wind turbines," International Electrotechnical Commission (IEC), IEC Central Office 3 rue de Varembé CH-1211 Geneva 20, Switzerland, International Standard IEC 61400-12-1:2017-03(en-fr), Mar. 2017.

[18] M. E. Okorie and F. L. Inambao, "Identification of Tower and Boom-Wakes Using Collocated Anemometers and Lidar Measurement," IJMET, vol. 10, no. 6, pp. 72-94, Sep. 2019.

[19] M. E. Okorie, F. Inambao, and Z. Chiguvare, "Evaluation of wind shear coefficients, surface roughness and energy yields over inland locations in Namibia," Procedia Manuf., vol. 7, pp. 630-638, Jan. 2017, doi: 10.1016/j.promfg.2016.12.094.

[20] M. E. Okorie, F. L. Inambao, Z. Chiguvare, and N. A. Kgabi, "Wind shear coefficients and energy yields estimations: Namibia case study of arid coastal and inland locations," Int. J. Appl. Eng. Res., vol. 13, no. 8, pp. 6282-6296, 2018.

[21] G. Gualtieri and S. Secci, "Wind shear coefficients, roughness length and energy yield over coastal locations in Southern Italy," Renewable Energy, vol. 36, no. 3, pp. 1081-1094, Mar. 2011, doi: 10.1016/j.renene.2010.09.001.

[22] G. Gualtieri and S. Secci, "Comparing methods to calculate atmospheric stability-dependent wind speed profiles: A case study on coastal location," Renewable Energy, vol. 36, no. 8, pp. 2189-2204, Aug. 2011, doi: 10.1016/j.renene.2011.01.023.

[23] A. Derrick, et al., "HAVSNÄS - Pilot project report on cold climate and high hub height on mate and high hub height," Göteborg Sweden, Renewable Energy Systems Ltd/NV Nordisk Vindkraft AB, 2012.

[24] I. Fyrippis, P. J. Axaopoulos, and G. Panayiotou, "Wind energy potential assessment in Naxos Island, Greece," Appl. Energy, vol. 87, no. 2, pp. 577-586, Feb. 2010, doi: 10.1016/j.apenergy.2009.05.031.

[25] A. N. Celik, "A statistical analysis of wind power density based on the Weibull and Rayleigh models at the southern region of Turkey," Renewable Energy, vol. 29, no. 4, pp. 593-604, 2004.

[26] S. A. Akdağ, H. S. Bagiorgas, and G. Mihalakakou, "Use of two-component Weibull mixtures in the analysis of wind speed in the Eastern Mediterranean," Appl. Energy, vol. 87, no. 8, pp. 2566-2573, Aug. 2010, doi: 10.1016/j.apenergy.2010.02.033.

[27] E. K. Akpinar and S. Akpinar, "Statistical analysis of wind energy potential on the basis of the Weibull and Rayleigh distributions for Agin-Elazig, Turkey:," Proc. Inst. Mech. Eng., Part A, Jan. 2006, doi: $10.1243 / 0957650042584357$.

[28] P. K. Chaurasiya, S. Ahmed, and V. Warudkar, "Study of different parameters estimation methods of Weibull distribution to determine wind power density using ground based Doppler SODAR instrument," Alexandria Eng. J., vol. 57, no. 4, pp. 2299-2311, Dec. 2018, doi: 10.1016/j.aej.2017.08.008.

[29] A. Pena and C. B. Hasager, "Remote sensing for wind energy," Risø National Laboratory for Sustainable Energy, Technical University of Denmark., Risø-I3184(EN), May 2011.

[30] G. Gualtieri, "The strict relationship between surface turbulence intensity and wind shear coefficient daily courses: a novel method to extrapolate wind resource to the turbine hub height," Int. J.Renewable Energy Res., vol. 5, no. 1, pp. 183-200, 2015, doi: 10.20508/ijrer.39363.

[31] M. E. Okorie, F. Inambao, and Z. Chiguvare, "Evaluation of Wind Shear Coefficients, Surface Roughness and Energy Yields over Inland Locations in Namibia," Procedia Manuf., vol. 7, pp. 630-638, Jan. 2017, doi: 10.1016/j.promfg.2016.12.094. 
International Journal of Engineering Research and Technology. ISSN 0974-3154, Volume 13, Number 11 (2020), pp. $3125-3144$

(C) International Research Publication House. https://dx.doi.org/10.37624/IJERT/13.11.2020.3125-3144

[32] G. Gualtieri and S. Secci, "Methods to extrapolate wind resource to the turbine hub height based on power law: A 1-h wind speed vs. Weibull distribution extrapolation comparison," Renewable Energy, vol. 43, pp. 183-200, Jul. 2012, doi: 10.1016/j.renene.2011.12.022.

[33] S. Rehman and N. M. Al-Abbadi, "Wind shear coefficient, turbulence intensity and wind power potential assessment for Dhulom, Saudi Arabia," Renewable Energy, vol. 33, no. 12, pp. 2653-2660, Dec. 2008, doi: 10.1016/j.renene.2008.02.012.
[34] S. Orlando, A. Bale, and D. Johnson, "Experimental study of the effect of tower shadow on anemometer readings," J. Wind Eng. Ind. Aeorodyn., vol. 99, pp. 16, Jan. 2011, doi: 10.1016/j.jweia.2010.10.002.

[35] R. N. Farrugia and T. Sant, "Modelling wind speeds for cup anemometers mounted on opposite sides of a lattice tower: a case study,” 2013, doi: 10.1016/j.jweia.2012.11.006G. 